\title{
Accessibility in the provinces of Finland
}

\author{
MARKKU TYKKYLÄINEN
}

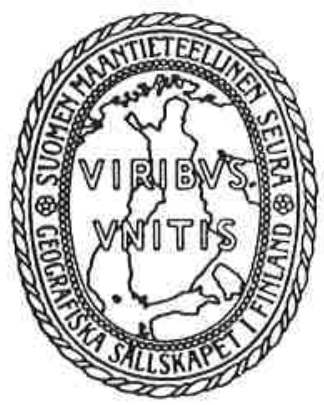

Tykkyläinen, Markku (1981). Accessibility in the provinces of Finland. Fennia 159: 2, pp. 361-396. Helsinki. ISSN 0015-0010.

\begin{abstract}
Relative, mean and integral accessibility in the existing provinces of Finland and in the proposed new provinces was studied applying graph theory, through evaluating the shapes of the provinces by reference to polygonal graphs, and, in a more detailed analysis, through using flow graphs to represent the accessibility between locations. The sensitivity of the accessibility structure was tested by means of two simulation experiments.

The poorest accessibility levels existed in the more northerly provinces, although some provinces weak in this respect could also be found in Southern and Central Finland, especially when accessibility was studied in relation to the size of the province. This correlates with a certain backwardness in the development of the administrative regions in relation to population development. The proposed province revisions have not corrected this situation entirely. The locations of the provincial capitals are close to the (pareto-)optimum in general, the non-optimal cases being ones in which the most significant centres of population growth have been located elsewhere than in the provincial capital or its immediate surroundings. Integral accessibility as a measure of optimal location is not sensitive to changes in spatial structure, and extremely large movements of population would be required to cause any substantial alteration in the location of the optimal centre.
\end{abstract}

Markku Tykkyläinen, Department of Geography, University of Joensuu, P.OB. 111, SF-80101 Joensuu 10, Finland; November, 1980.

Aims of the study

Changes in the regional administrative structure and research traditions . .............. Development of the administrative provinces of Finland .................. 362 Plans for the revision of the spatial structure of the provincial administration ..... 364 Research into accessibility and regional structures in Finland ............... 365

Accessibility within the framework of graph

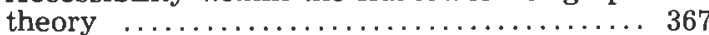

Theoretical traditions .............. 367

The graph theory approach ............. 367

The measurement of accessibility ...... 369

The provinces of Finland as graphs 374
Accessibility in the existing and proposed new provinces $\ldots \ldots \ldots \ldots \ldots \ldots \ldots \ldots \ldots \ldots . \ldots \ldots$

Shape of the province .............. 375

Mean and relative accessibility $\ldots \ldots \ldots . \ldots 376$

Optimum location and integral accessibility

of the provincial capitals ............ 379

Effect of the provincial capital upon in-

tegral accessibility ................. 384

Maximum distance as a criterion for ac-

cessibility ........................... 390

Conclusions $\ldots \ldots \ldots \ldots \ldots \ldots \ldots \ldots \ldots \ldots \ldots \ldots \ldots$

Accessibility findings ................. 391

Methodological evaluation .............. 393

Acknowledgements ................... 394

References ........................ 394

This phenomenon is frequently discussed under the heading of 'accessibility'. The present division of Finland into administrative provinces and the plans for revising this may then be seen as providing an interesting topic for research in this field. What 
is the nature of accessibility in the existing provinces, and will it improve as a result of the revisions proposed? And again, are the central places of the provinces located in such a manner as to maximize accessibility? The problem becomes a particularly interesting one when we recall that the present system of provinces in Finland and the proposed revisions are the results of a long, extensive process of democratic development and evaluation. To what extent can a combination of democratic decision-making and planning succeed in reaching optimal solutions with regard to accessibility?

The research to be presented here follows the methods of graph theory, and all the measures of accessibility are handled in a consistent manner on the basis of this theory, the material for the individual provinces consisting of undirected graphs depicting form and interconnections. These graphs are analysed using the algorithms of graph theory and the respective indices of accessibility calculated from these. The methods of graph theory are then elaborated further so that they may be applied to the analysis of changes in accessibility, and the sensitivity of the spatial structure to such changes is examined by simulating the spatial structures of the provinces. Thus the work also has a methodological purpose in the treatment of accessibility within the framework of graph theory.

The regional structure of the provinces of Finland has been studied and planned both in scientific research associated with the division of the country into administrative units at the intermediate level and in the many reports and plans produced by select committees and the Ministry of Internal Affairs. The latest plan for the reorganization of the provinces was issued in 1978 (Committee for Revision of the Provincial Boundaries 1978), and represents the outcome of a long period of research, investigation and planning. Should it be decided to form new provinces in the near future, this would presumably take place according to the above plan.

The creation of spatial systems and the study of their structure is a highly complex task. A spatial structure can comprise a large number of elements differing in their properties, so that the same kinds of problem arise in reducing them to some common measure as are encountered in the construction of a welfare function. Thus the present work concentrates on one crucial aspect of the regional structure in Finland, accessibility in the administrative provinces.

\section{Changes in the regional administrative structure and research traditions}

\section{Development of the administrative provinces of Finland}

The division of Finland into provinces has undergone numerous changes over the centuries, and the present scheme is the result of a combination of very many different factors. The administrative provinces derive their origin from the medieval provinces, which were principally of civil and juridical significance, and from 'castle' provinces set up for military purposes. As the importance of these military provinces increased they acquired jurisdiction over civil matters. The administrative provinces were established at the beginning of the 17th century for the general representation of the central administration without any military or juridical tasks. Four provinces, were recognized, each extending from the coast towards the interior of the country (Fig. 1). The division was later affected by the wars and boundary changes experienced in Eastern Finland in the early part of the same century (Committee Report 1974: 38). In these early days of regional government the population of Finland was concentrated mainly along the coasts, while the inland areas served as a hinterland. Accessibility was important to the coastal towns, through which administrative affairs and trade were organized (e.g. Ajo 1946).

The troubled times were over by the latter part of the 18th century, and in the interests of physiocracy settlements were set up especially in Ostrobothnia, and also in Karelia and other parts of the country. Accessibility between Eastern Finland and the south coast deterioriated because of the changes in boundaries caused by wars at the beginning of the century. In 1775 the eastern part of the 

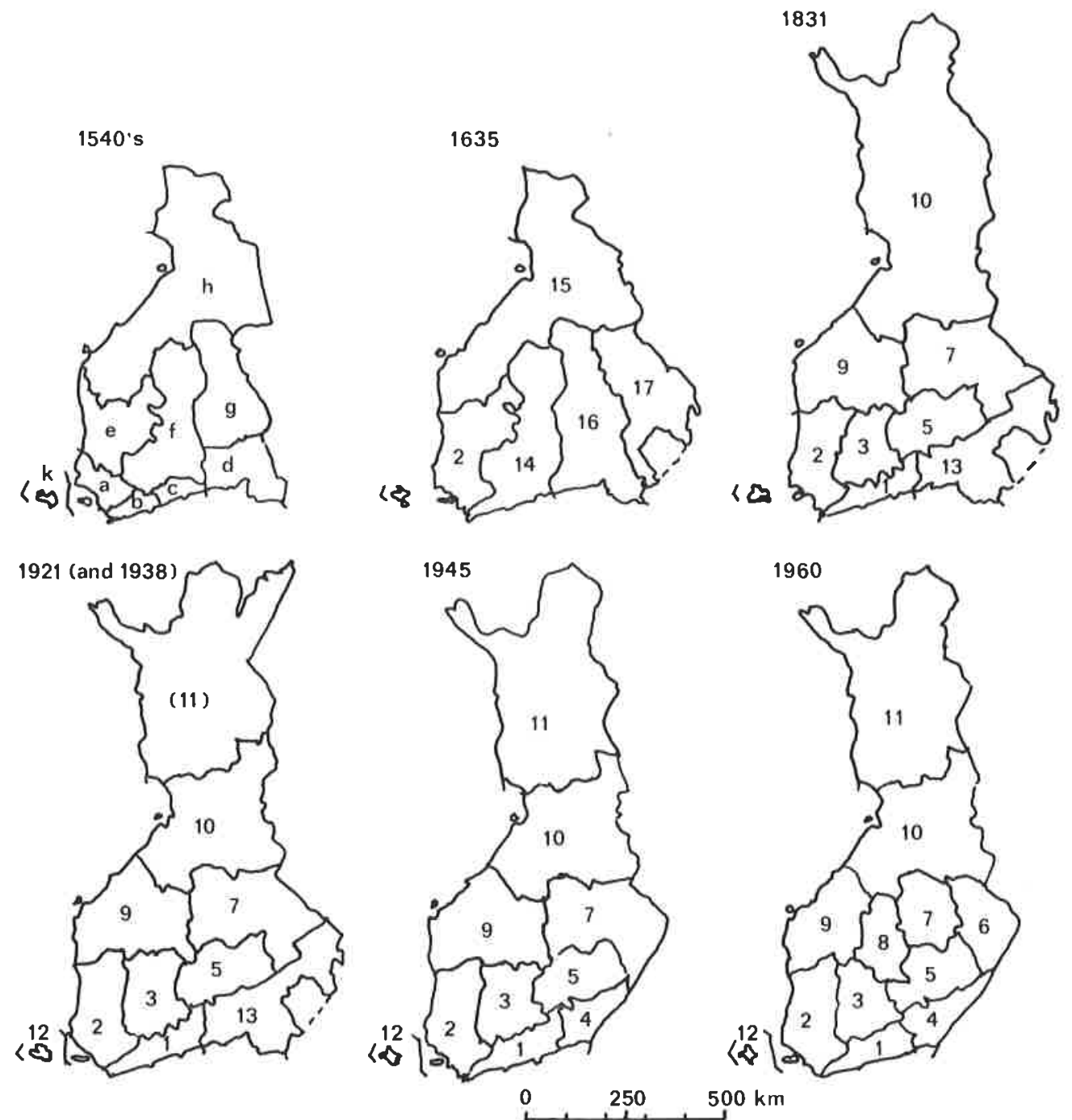

Fig. 1. History of the Finnish provinces, I540-1960 (Jutikkala 1959: 32-34, Map of Finland 1923: I-V, Committee Report 1974: 40). Provinces (for military purposes): (a) Turku, (b) Raasepori, (c) Porvoo, (d) Viipuri, (e) Kokemäenkartano, (f) Hämeenlinna, (g) Savonlinna, (h) Korsholma and (1) Kastelholma. Administrative provinces: (1) Uusimaa, (2) Turku and Pori, (3) Häme, (4) Kymi, (5) Mikkeli, (6) Northern Karelia, (7) Kuopio, (8) Central Finland, (9) Vaasa, (10) Oulu, (11) Lapland, (12) Ahvenanmaa, (13) Viipuri, (14) Uusimaa and Häme, (15) Ostrobothnia, (16) Viipuri and Savonlinna, and (17) Käkisalmi.

country was divided into two provinces, those of Kymi on the coast and Savo and Karelia inland, while the province of Ostrobothnia was subdivided into those of Vaasa and Oulu. Population growth and progress in primary industries and trade from the latter part of the 18th century onwards were greater inland than on the coasts. Development in Uusimaa was stimulated principally by the creation of the new national capital of Helsinki. In 1831, Uusimaa and Häme were distinguished as two separate provinces and the southern part of Savo was recognized as a discrete province of Mikkeli (Fig. 1). Considerable changes in the administrative structure were carried out just before the Second World War and again after it (Fig. 1). The two newest provinces, Central Finland 
and Northern Karelia, were founded by a statute promulgated in 1956, which nevertheless came into force only in 1960 (Fig. 1).

Since the Middle Ages the alterations in the division of the country into provinces have happened without any fundamental or radical changes. The boundaries are the result of a long period of development, and most of them have been quite stable in time. Changes have been affected largely by wars and socio-spatial development. In broad outline, there is some correspondence between human spatial behaviour and the spatial administrative structure, even though the degree of this correspondence has varied in the course of time. The administrative provinces are one part of the administration at the level between state and communes (here called the intermediate level). Trends since the 19th century have led to the establishing of many branches of administration as independent organizations, in many cases with a separate system of district units. Cooperation between communes started in the early part of this century, and this has taken place in a diffuse manner, with the necessary administrative boundaries growing up on an ad hoc basis. Nevertheless the administrative provinces have become important regional units, and their capitals are with only two exceptions the largest centres in the area.

\section{Plans for the revision of the spatial structure of the provincial administration}

Revision of the spatial structure of the provincial administration has been under discussion on several occasions, and these plans have been realized with varying success. Several new reports on the division of the country into administrative provinces have been produced since the Second World War. The Regional Divisions Committee (Committee Report 1953) proposed a system of 15 provinces, including the creation of new provinces of Central Ostrobothnia, Central Finland, Northern Karelia, Pori and Tampere. This led to a law of 1956 creating the new provinces of Northern Karelia and Central Finland, although these began to operate only from 1960. None of the others were ever implemented in spite of the many plans to do so (Committee Reports 1960, 1962, 1965 and 1967).

Particular attention has subsequently been paid to the proposal to recognize the areas of Tampere and Satakunta as separate provinces, and this question was raised again in the report of the Committee on Regional Government (Committee Report 1974), in which they were referred to as the provinces of Pirkanmaa and Satakunta. The same report also contained a proposal for a province of Kainuu, but not Central Ostrobothnia, even though an earlier committee set up to discuss this question had recommended this (Committee Report 1967). The Committee on Regional Government made no proposals for changes in the provincial boundaries, but instead a separate working group was set up for this purpose, which produced its report in 1976 (Report of the Working Group on Regional Government Boundaries 1976). The recommendations nevertheless did not meet with unreserved approval at the commune level.

A new Committee for Revision of the Provincial Boundaries was then formed in 1977 with the task of investigating the indeterminacies existing in the present division into provinces and making recommendations for changes. This committee published its findings in 1978 (Committee for Revision of the Provincial Boundaries 1978). These were based on statements received from local and regional authorities and the outcomes of numerous open discussions arranged with local officials and elected representatives. The committee is to a large extent in favour of the present provincial boundaries, and draws the boundaries of the new provinces substantially along existing lines (Fig. 2). The greatest systematic departure from this concerns the boundary between the new provinces of Satakunta and Pirkanmaa, which does not follow the existing delimitation line between the provinces of Häme and Turku and Pori. The proposal as a whole departs markedly from that of the Working Group on Regional Government Boundaries (1976), which involved the transfer of many individual communes from one province to another, since their conclusions have frequently been strongly influenced by the opinions of the commune authorities on the preservation of existing provincial boundaries. 
This report (Committee for Revision of the Provincial Boundaries 1978) represents a solution to the question of the system of provinces and their boundaries, at least for the time being, and no new bodies have been nominated with the task of investigating any possibilities deviating from these proposals, although new needs are bound to arise with time, and these will have to be taken into account in revising the regional structure of the provincial administration.

The development and revision of the system of provincial administration, as with other planning and administrative systems, may be viewed as a continuous process of adapting regional structures to the changes occurring in society. Most of the proposals made since the Second World War include two new provinces, those of Satakunta and Pirkanmaa, and Kainuu has also been suggested as a possible independent province in recent years. The other proposed changes have aroused less support, however, although the idea of a province of Central Ostrobothnia still appeared in reports during the 1960's. All in all, some degree of unanimity has been reached on the revisions necessary, and an extensive process of evaluation made be said to have been carried through. The most recent proposals represent a thorough-going recommendation which will provide a basis for the revision of the regional structure of administration at the provincial level for a long time to come (Jarkko 1978).

\section{Research into accessibility and regional structures in Finland}

Many methods have been used for studying regional structures at the intermediate (province) level of administration. Particular attention has been paid to accessibility in quantitative research based on optimization methods, although the accessibility of services has also been taken into account to some extent in evaluations of central place systems and spheres of influence. Studies have also been carried out based on provincial identity amongst the population.

In his research into the accessibility of services within the Finnish network of population centres, Hakala (1973) employed return bus fares as a measure of accessibility, together with the cost of the time taken up

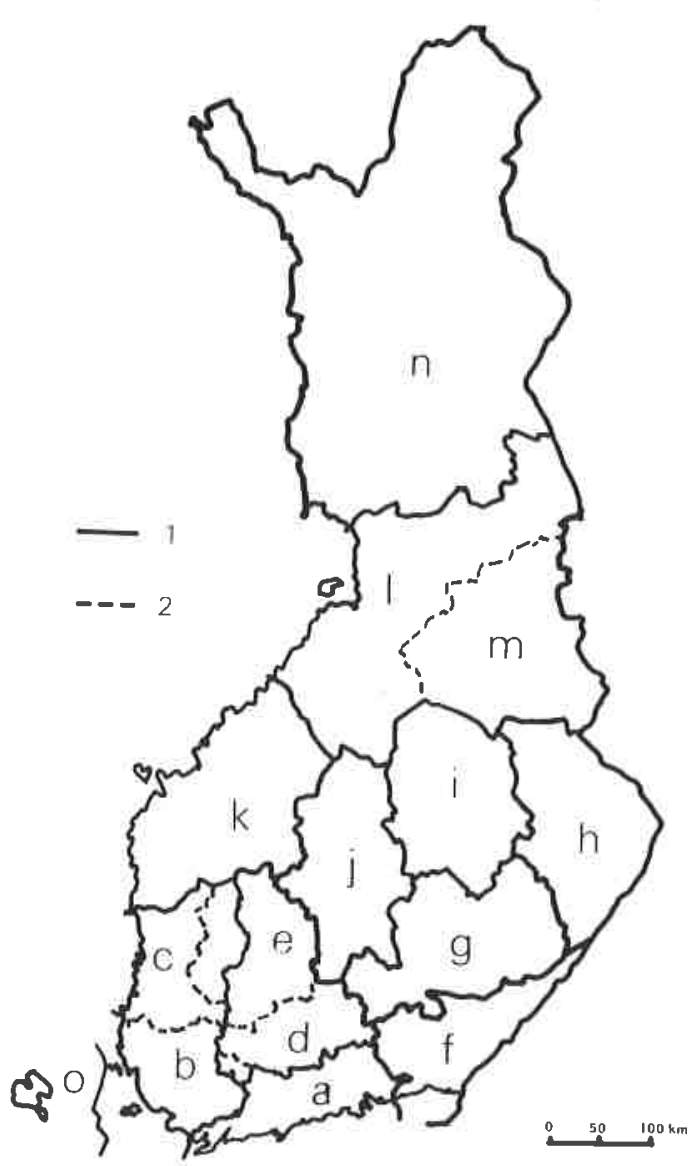

Fig. 2. Proposed new provincial boundaries (Committee for Revision of the Provincial Boundaries, 1978). (1) present boundary and (2) proposed new boundary. Provinces: (a) Uusimaa, (b) VarsinaisSuomi, (c) Satakunta, (d) Southern Häme, (e) Pirkanmaa, (f) Kymi, (g) Mikkeli, (h) Northern Karelia, (i) Kuopio, (j) Central Finland, (k) Vaasa, (1) Northern Ostrobothnia, (m) Kainuu and (n) Lapland.

in availing oneself of these services expressed as a proportion of an employed person's daily expense allowance. These costs were calculated on the basis of actual journeys undertaken to centres at the provincial capital, town, small borough and commune centre level. In his results, Hakala reports the highest level of accessibility to be achieved in the Uusimaa area, the second best in Southern Häme and the third best in Southeastern Finland. Northern Karelia, Lapland and Central Ostrobothnia proved to be areas 
of poor accessibility, and the worst district of all was that of Kainuu.

Accessibility was also studied by Kai-Veikko Vuoristo $(1967,1977)$ in connection with his road network analyses. His work is based principally on the formation on unweighted graphs and the calculation of indices from these networks. His study of the road network over the whole country (Vuoristo 1977) identifies Lapua in the province of Vaasa as the place of maximum accessibility, followed by Helsinki, Kouvola, Lahti, Mikkeli and Tampere. He also discusses the significance of the road network for the regional structure of the country and its economy on a very general level.

The research published by Palomäki in 1968 on the division of the country into provinces compares the central place structure obtained by the Commercial Research Institute by an enumerative method (LTT 1967) and a set of spheres of influence constructed from interviews with teachers with a division into provinces on the basis of public opinion. Although this research does not contain any analysis of accessibility based on distance or cost factors, the division obtained from public opinion may be regarded as giving expression to a certain optimal structure of accessibility based on social and cultural identity. Comparison of this intuitive division with that contained in the central place and sphere of influence model (LTT 1967) and the actual system of provinces shows the former to reveal one or two new areal units, mostly comprising subdivisions of the existing provinces. The provinces of Oulu and Lapland, for example, fall into five perceptual regions, Lapland, Peräpohjola, Koillismaa, Northern Ostrobothnia and Kainuu, the first three of which are not advanced as possible new provinces in any of the committee reports quoted above.

The emergence of the coastal area around Vaasa as a separate region both functionally and psychologically is to be expected, since most of the inhabitants of this coastal strip are Swedish-speaking, while the recognition of the southern part of Karelia and the Kymi valley as regional units in the same way may be an indication of the fragmentary regional structure in the area brought about by the change in the national boundary. Other problematical regions as far as the present system of provinces is concerned seem to be Häme and the southern parts of Central Finland. Central Ostrobothnia has been proposed earlier as a possible new province, in 1967, but unsuccessfully, while the province of Turku and Pori falls into two psychological regions which may be termed Varsinais-Suomi and Satakunta, the boundaries of which follow approximately the same pattern as those proposed by the Committee for Revision of the Provincial Boundaries in 1978 for new provinces of the same names. The northern parts of the province of Häme stand out as an intuitive region of Pirkanmaa more or less coincident in its boundaries with the proposed new province, but the region of Häme to the south of this proves somewhat larger than the proposed new province of Southern Häme, comprising in addition the southern parts of the province of Central Finland and the western parts of that of Mikkeli. In other respects the proposals for the new system of provinces seems to follow quite closely the division obtained on the basis of popular opinion.

Palomäki (1972) also evaluates the plans for revising the system of administrative regions, using largely the same material as for his earlier work (Palomäki 1968). One object of scrutiny is the proposal made by the Committee for determining the Organizational Form of Cooperation between Communes (Committee Report 1970). The most problematical areas as far as provincial administration and the hierarchy of centres are concerned are seen to be South-eastern Finland, Southern and Central Ostrobothnia and Southern Häme. Otherwise he regards the division put forward in the report as highly satisfactory (Palomäki 1972: 11-13).

The optimization studies of Takanen (1972) operate with numerous alternative divisions at the level of intermediate administration, each of which is assigned an index in respect of population, distance, centrality and directionality factors. Takanen does not discuss the theoretical bases for his work to any great extent, nor does he consider the possibilities for its application, contenting himself with presenting the calculations as such.

The work of Hautamäki (1972) examines the optimality of the national hierarchy of centres both by linear programming and using the p-median. The material comprises 17 centres. He applies linear programming 
by allowing the method to indicate the minimum number and distribution of transportation events for each network of centres examined. By altering the structure and repeating the program, it is eventually possible to select the best alternatives out of the results of the analysis and thereby to find the optimum solution. In the case of the p-median, the method itself chooses directly the optimum combination of centres by minimizing the distance sum. The two methods gave very similar results, and with the highest $p$ value $(p=7)$ the optimum combination of centres was Helsinki, Kuopio, Oulu, Tampere, Turku, Vaasa and Mikkeli.

A decline in research into the evaluation of regional structures at the intermediate level from a scientific point of view may be noted subsequent to the publication of the work referred to above. A stage had undoubtedly been reached at which research to date, together with the facts already documented and the numerous committee reports submitted, could provide an adequate starting point for future committees and working groups.

\section{Accessibility within the framework of graph theory}

\section{Theoretical traditions}

The activities of the administrative sector are communicated to the population at large through the medium of the public services. Such services possess the essential characteristics of being independent of market forces in their price levels and utilization, the provider of such services being a monopoly which does so either free of charge or at a purely nominal fee. Few alternatives are offered to these services, and their use may be either voluntary or obligatory for the general public. It is very often difficult to specify whom such services are directed at on the individual level, particularly in the case of services defined as general functions or those intended to ensure the basic smooth running of the community, most of which are directed in common at all those living in a given area.
Much of the research dealing with administrative regions or central place structures sets out from the central place and sphere of influence theories. The assumptions made in the theory of Christaller are enumerated by Eliot-Hurst (1972:198) and those of the theory of Lösch by Paelinck \& Nijkamp (1975: 60). These are highly rigorous, and most of them apply more readily to the examination of the structures of market regions rather than administrative regions. The assumptions made in the theories of Christaller (1933/1966) and Lösch (1940/1954) are in many ways similar. Both assume that in a state of competition an areal system is formed on a homogeneous plane in euclidean space. For Lösch the concept of area is a purely economic one, whereas Christaller also gives it a political or administrative character, although the assumptions and structure of his theory are still based on allocation according to a market-based mechanism. The assumptions of a homogeneous plane are entirely divorced from reality, and the processes of political and administrative decision-making do not function according to the laws of a market-based mechanism. The problems associated with a homogeneous euclidean plane are discussed by such authors as Isard (1956) and Rushton (1972), although these do not deal explicitly with the foundations of the administrative and political allocation mechanism.

Research into questions of location and accessibility has also been carried out from other standpoints. The location of public services and the establishment of administrative regions have been approached in the manner of a distance minimization problem using the concepts of operational analysis. Terms such as 'minisum' and 'minimax' location problems, combined with the conceptual framework of graph theory, offer a valuable supplement to the central place and sphere of influence approach when discussing problems of accessibility, the location of administrative centres and the delimitation of their regions.

\section{The graph theory approach}

Graph theory is an abstract system of mathematical concepts which has been applied to research in a variety of fields. The 


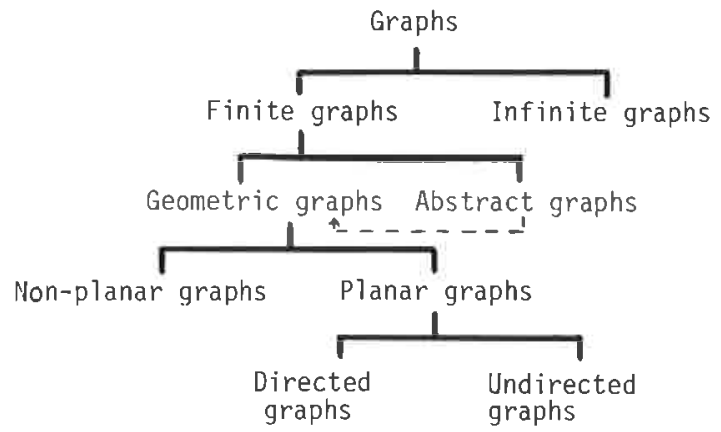

Fig. 3. Classification of graphs by their properties. The broken line denotes that every abstract graph has its geometric counterpart.

history of the theory is of particular interest from the geographer's point of view, since it has been associated with the solution of geographical problems from the very outset. The starting point for the theory is the solution proposed by Euler in 1736 for the famous problem of the bridge at Königsberg (present Kaliningrad). A number of problems in graph theory aroused general interest during the 19 th century, including the 'four-colour conjecture' for maps put forward by Moebius in 1840 and the 'Icosian Game' or a 'Voyage Round the World' proposed by Hamilton in 1859 (Deo 1974: 10), both of which have inspired a great deal of further research. The former problem was solved in 1976 by Appel \& Haken (1977), but it has so far proved impossible to find a general solution in an arbitrary graph to the latter.

Graph theory nevertheless only began to be used extensively in the solution of geographical problems in the 1960's, when it was applied to the central place and sphere of influence theories and also in the empirical testing of these theories (e.g. Medvedkov 1967; Nystuen \& Dacey 1961; Garrison 1960), research which has close links with the verification of the general topological properties of these theories (see Dacey 1965, Marchand 1973). Graph theory has also been used in solving spatial location problems and in the analysis of communications networks.

The central concept in graph theory is that of the graph itself. Graphs may be classified in the manner depicted in Fig. 3, which omits the subsequent subdivisions of types not of interest for geographical research. The interest from the geographical point of view centres in particular upon the planar graphs, which can in turn be divided into directed and undirected types. Haggett also proposes a further classification of graphs, according to the purpose for which they are used, into those in which the edges depict flows and those in which they depict barriers (Haggett \& Chorley 1974: 7). Kansky (1963) defined the concepts of graph theory as suitable for spatial evaluations, and Bunge (1966: XIII, 200) stated, admittedly indirectly, that the connections between graph theory and central place and sphere of influence theory was fundamentally a problem of the p-median. The majority of research on accessibility and routes of communication makes use of graph theory to some extent or other, either to develop a theoretical foundation for optimal networks or in creating possible applications for the study of spatial structures.

The algorithm developed by Törnqvist et al. (1971) for the solution of location problems is based on a grid, but the problem may also be described in terms of graph theory. This algorithm has since gained in currency and has been used frequently in recent years (e.g. Robertson 1976, 1978). Optimization algorithms based on graph theory have been used in Finland both in the work of Hautamäki (1972) and for optimization within small areas (Aira et al. 1972; Optimization of School Places 1973; Nurminen 1976).

The practical application of graph theory has been hampered by the lack of efficient algorithms. Particular topics of research and discussion have been an efficient solution to the problem of the p-median (Hakimi 1965) and the further elaboration of algorithms. Difficulties have been experienced in arriving at a really efficient algorithm. Algorithms have been speeded up by eliminating the most improbable alternatives, which has simplified the search procedure, but this has then given a heuristic solution which represents only an approximate result at a given risk level. It has not proved possible to render the solution of the p-median problem any more efficient by means of a purely mathematical unique solution, for instance.

The present work makes use of undirected planar graphs to describe both barriers and flows. Those describing barriers are referred to as polygonal graphs and are used to depict the form of the administrative regions, while those describing flows are employed in cal- 
culating the indicators of accessibility. Of the various algorithms available in graph theory, that of Floyd is used to transform the original graph into a complete graph in forming the distance matrix. The graphs are used for the calculation of the centre point, radius, absolute centre and radius, and the median. In addition, the percentage deviations in integral accessibility of the commune centres in relation to the optimal centres are calculated for the purposes of spatial comparison. The p-median is calculated for the province of Oulu using a non-heuristic algorithm. Two simulation systems are used to study the permanence of the accessibility index, entailing repetition of the majority of the above analyses. Certain statistical measures, such as the mean, standard deviation and coefficient of variation, are also calculated for the graphs.

\section{The measurement of accessibility}

\section{Accessibility as a concept}

Accessibility is a geographical term which is frequently used either alone or as a synonym for 'distance base' terms. Often it is defined via its operational equivalent, in which case the problem of defining it is avoided, together with the question of the validity of the measure used for assessing the term. If one sets out from the theoretical concept, however, it may prove difficult to define the term and equally difficult to find its operational equivalent. This leads Gould (1969: 64) to state that accessibility is a common term which everyone uses until they come up against the problems of defining and measuring it. Ingram (1971: 101) defines accessibility as the property of a place in respect to the extent to which it can overcome spatial friction. Thus it can be defined as the relative status of some place in a space.

Ingram (1971: 101-102) distinguishes two concepts of accessibility: relative accessibility and integral accessibility. The former is defined as the degree to which two places or points are connected on the same surface, and the latter as the degree to which one place or point is connected with all the other points on the same surface. The relation between relative and integral accessibility may be defined as
(1) $D_{i}=\sum_{j=1}^{n} d_{i j}$

where $D_{i}$ is the integral accessibility of the place $i$ and $d_{i j}$ the relative accessibility of point $j$ at point $i$.

The operational correlate of the relative accessibility $d_{i j}$ is expressed by the function

(2) $d_{i j}=f\left(a_{i j}, c_{i j}, \ldots, t_{i j}, t_{i}, t_{j}\right)$

in which the arguments serve to depict quantities such as distance, travel costs or travelling and waiting time. An operational correlate of accessibility can be assumed to contain some combination of the above variables, or even other variables. The parameters of a function describing accessibility are usually empirical constants.

The present work employs distance by road as a measure of accessibility. The population data are obtained for individual communes and the distances calculated between the commune centres. The concept of accessibility is interpreted in a highly simplified sense here, although the inclusion of such variables as travel and waiting time, quality of the roads, the flow of information, etc. would probably not have affected the results very markedly since these usually correlate closely with one another. Some of the results achieved here even suggest that the accessibility values would remain valid in spite of changes in the spatial structure.

Some criticism has been made of research into both transport and accessibility in recent years (Breheny 1978), largely concerning the methodological approaches used and the selection of variables to describe accessibility. According to Breheny (1978: 464), the tradition of research in this field may be divided upon two dimensions: (1) whether the description is based on travel behaviour, either observed or simulated, or whether the measures are based on a survey of spatial possibilities without any functions representing behaviour, and (2) whether or not interaction is assumed to decline with increasing distance. If one wishes to describe human behaviour, however, and simulate it as accurately as possible, it would seem justified to take such behaviour into account, together with the effect of distance as a factor tending to reduce interaction and the effects of other centres as competing forces of attraction. Assumptions of the above kind 
have been made in certain studies on central place networks in Finland which have attempted to predict centrality on the basis of population figures and the influence of the nearest other centres, taking into account the distances between the centres. The results have been analyses of the existing spatial structure and its presentation in the form of a quantitative model (Palomäki \& Mikkonen 1972) and a trend-like projection for the future regional structure (Mikkonen 1975).

Accessibility should nevertheless be regarded as a variable which is independent of behaviour. Thus inclusion of behaviour in the operational model will introduce the following weaknesses:

(1) The existing spatial structure may restrict accessibility to a considerable extent, in which case the estimated parameters will produce a non-optimal model from the individual point of view.

(2) If the existing spatial structure is used to project future states, the existing inefficiencies and inconsistencies will be reflected in the planned future state.

(3) The measures refer to actual travel behaviour and not the need for contact between individuals, which may depart markedly from the actual situation.

(4) The models will not reflect differences in preferences between population groups.

As Breheny is able to demonstrate, accessibility should be measured for planning purposes on the basis of the opportunities offered in an area, without regard for the influence of distance upon demand. The estimation of parameters in planning models from the existing spatial structure has also been criticized by Lee (1973: 165) and Wachs \& Kumagi (1973: 441-442), for instance.

A number of aims and constraints have been proposed for the measurement of accessibility:

(1) Analyses of accessibility should not content themselves with quantifying the existing situation, but an attempt should be made to compare this accessibility with that obtainable in alternative spatial structures, defining the alternatives in such a way that they are capable of realization. This realism requirement should in particular be built into any research intended for use in planning.

(2) The planning of spatial structures should set out from the optimal or best available alternative and not be merely a continuation of the existing situation.

(3) Individuals should be treated equally in the model, so that the place of residence of any individual does not affect his need for contacts as depicted in the model. This removes the necessity for a distancedecay function in the evaluation of accessibility.

(4) Any preferences noted among population groups should be taken into account in the model.

The above considerations are taken note of in the present work. Accessibility is studied in alternative spatial structures and although no projection or planning aim is stated explicitly, future prospects are examined by means of a comparison between the present situation and the best alternative. The analyses provided here are based on models which do not allow for any decline in demand with distance. As we are concerned here with accessibility in general, however, the citizens are considered on an equal footing, and no preferences among population groups are distinguished. If it had been a question of some individual service such as children's day nurseries in a limited area, for instance, some examination of preferences would have been justified, but where accessibility in general is being considered, such differentiation is difficult and could lead to an unequal interpretation.

Graph theory in the description of the shape of an area

Accessibility is dependent on the shape of the area concerned, a feature which may be described using polygonal graphs. As early as the 17th century, Kepler was interested in the problem of filling a plane with areas of optimal accessibility. The optimal area is of course a circle, but circles cannot be placed on a plane in such a manner as to cover the whole surface without their intersecting. The edges in a polygonal graph, $\mathrm{E}=\mathrm{e}_{1}, \mathrm{e}_{2}, \ldots$, $\left.e_{i}, \ldots, e_{m}\right\}$, describe the boundaries of the areas, and the nodes, $V=\left\{v_{1}, v_{2}, \ldots, v_{j}, \ldots\right.$, $\left.\mathrm{v}_{\mathrm{n}}\right\}$, their intersections. The areas themselves may be denoted by $W$, where $W=\left\{w_{1}, w_{2}, \ldots\right.$, $\left.\mathrm{w}_{\mathrm{k}}, \ldots, \mathrm{w}_{\mathrm{f}}\right\}$. Euler was the first to demonstrate the structural property of a polygonal graph that 
(3) $\mathrm{n}-\mathrm{m}+\mathrm{f}=2$.

When examining the structure of polygons against the condition that the polygons should fill a given plane completely, this rule of Euler's gives for regular polygons

(4) $1+\frac{\mathrm{p}}{\mathrm{p}^{*}}=\frac{\mathrm{p}}{2}$ or $(\mathrm{p}-2)\left(\mathrm{p}^{*}-2\right)=4$

where $p$ is the degree of a node in a regular graph and $p^{*}$ the number of edges surrounding a polygon, or area (Ore 1963: 99$108)$. This condition is fulfilled only by systems of triangles $\left(p=6, p^{*}=3\right)$, squares $(p=$ $\left.p^{*}=4\right)$ and hexagons $\left(p=3, p^{*}=6\right)$, and thus only these among the regular polygons will fill a plane entirely. The best solution as far as accessibility is concerned is therefore that polygon from the above set in which the maximum distance from the centre to each side is shortest.

If we take a regular triangle, square and hexagon of equal area $\left(A_{1}=A_{2}=A_{3}=1\right)$ and let $\mathrm{q}$ be the circumference of the polygon and $\mathrm{g}$ the maximum distance between the centre and the edge delimiting the polygon, we obtain the structural properties for each of these polygons: $\mathrm{q}_{1}=4.56, \mathrm{~g}_{1}=.88, \mathrm{q}_{2}=$ $4.00, g_{2}=.71, q_{3}=3.72$ and $g_{3}=.62$. The data suggest that the hexagonal structure should be regarded as the best in terms of accessibility, as it is this that achieves the minimum value for the maximum distance on a homogeneous surface. It also proves the most advantageous in terms of the combined lengths of the delimiting edges. Paelink \& Nijkamp (1975: 72-77) show a hexagonal structure to be the most advantageous in terms of mean accessibility.

A number of indices have been developed for evaluating the optimality of the shape of an area (Haggett \& Chorley 1974: 70, summary), one of the simplest of which is Haggett's index of shape

(5) $\mathrm{S}=1.27 \mathrm{~A} / l^{2}$

in which $l$ is the distance between the most remote points in the area. The index has values ranging from 0 to 1 , since it serves in effect to compare the shape of the given area with a circle of the same diameter:

(6) $\frac{\mathrm{A}}{\frac{\pi\left(-\frac{1}{2}\right.}{2}}=1.27 \mathrm{~A} / h^{2}$
An areal structure composed on hexagons would have a value of 0.83 for Haggett's index. It would thus be equally reasonable to employ the index

(7) $\mathrm{S}^{\prime}=\frac{\mathrm{A}}{2.598\left(\frac{1}{2}\right)^{2}}=1.54 \mathrm{~A} / h^{2}$

in which the shape of the given area is compared with a regular hexagon of the same diameter, which would assign the value 1 to the optimum shape, the hexagon itself. The indices may be compared using the following transformations: $\mathrm{S}^{\prime}=1.21 / \mathrm{S}, \mathrm{S}=.83 \mathrm{~S}$.

\section{Graph theory for the analysis of connections}

For the analysis of connections the set $\mathrm{E}$ of edges of the graph is taken to denote the connections between the locations in the given area. These connections may involve the passage of information, transport communications, or any other form of interaction, and the values assigned to them may be either estimated from the real situation or consist of probabilities or potentials. For the purpose of spatial accessibility and optimization studies these connections are usually depicted in terms of distances along main roads (cf. Hautamäki 1972, Aira et al. 1972).

The nodes of the graph $\left(\mathrm{v}_{\mathrm{i}} ; \mathrm{v}_{\mathrm{i}} \in V\right)$ stand for locations, e.g. centres, individual residential areas, or even single homes. In the present case they are taken to represent commune centres. The distance between nodes $v_{i}$ and $v_{j}$ is then defined as the sum of the weightings assigned to the shortest edge or sequence of edges in the graph by which they are united. Thus the distance $d_{k i j}$ between the nodes $v_{k i}$ and $v_{k j}$ indicates the shortest distance by main road between the commune centres $i$ and $j$ in the province $k$.

The resulting matrix $D_{k}$ of distances between the commune centres of a given province $\mathrm{k}$ serves as the starting point for the study of accessibility in that province. The distance matrix is formed by taking the value 1 for $i\left(d_{k 1 j}\right)$ as representing the distances from the provincial centre to the other commune centres in the province. The matrix can then be used as a basis for the calculations either in this form or else after transformation in terms of costs or frequency of transit. This 
distance matrix and its transforms serve as the starting point for the spatial simulation and optimization processes, and can also be used to calculate indices of spatial structure and accessibility. Comparison of a number of areas of differing size may also involve description of their relative by means of indices obtained by standardization procedures.

\section{Relative and mean accessibility}

The concept of relative accessibility is used here to analyse accessibility between the provincial capitals and the main villages of the communes. It is then possible to study to what extent the population is located in areas whose relative accessibility with respect to their provincial capital differs from the mean value. The two measures are inversely related to more conventional ones, however, in that low values for $d_{k i j}, \bar{x}$ and $\overline{\mathbf{x}}_{\mathrm{ki}}$ are associated with good accessibility. The same is true for integral accessibility. The national mean accessibility for a population with respect to its provincial capital is obtained from the equation

(8) $\overline{\mathrm{x}}=\frac{\sum_{\mathrm{k}} \sum_{\mathrm{j}} \mathrm{h}_{\mathrm{kj}} \mathrm{d}_{\mathrm{kij}}}{\sum_{\mathrm{k}} \mathrm{m}_{\mathrm{k}}}(\mathrm{i}=1)$,

in which $h_{k j}=$ the population of commune $j$ in province $k, d_{k i j}=$ the distance of the centre $\mathrm{j}$ from the provincial capital $\mathrm{i}$ of the province $\mathrm{k}$, and $\mathrm{m}_{\mathrm{k}}=$ the population of the province $\mathrm{k}$. The mean accessibility of the capital $\mathrm{i}$ of province $\mathrm{k}$ is thus

(9)

$$
\overline{\mathbf{x}}_{\mathrm{ki}}=\frac{\sum_{\mathrm{j}} \mathrm{h}_{\mathrm{kj}} \mathrm{d}_{\mathrm{kij}}}{\mathrm{m}_{\mathrm{k}}} \text {. }
$$

Given a normal distribution of population, exactly $50 \%$ would be living further away from the centre than the distance implied by the mean accessibility both over the whole country and in the provinces individually. The standard deviation is defined by the equation

$$
s_{k i}=\sqrt{\frac{1}{m_{k}} \sum_{j} h_{k j}\left(d_{k i j}-\bar{x}_{k}\right)^{2}}
$$

For the purposes of the analyses the standard deviation in the accessibility of the provincial capitals throughout the country is determined from the equation
(11)

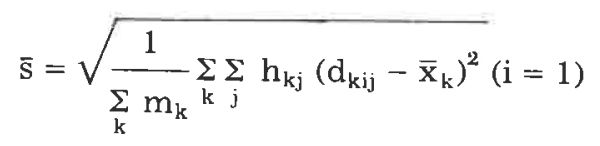

More detailed results could be obtained by dispersal of the data by types of services and utilizer groups, and the edges depicting the connections could similarly be differentiated. The situation is more problematical in practice, however, as ready-calculated statistics are scarcely ever available at this level, while even one such dispersal would increase the number of figures to be handled by several tens of thousands.

\section{Integral accessibility}

The operational correlate of integral accessibility as defined by Ingram (1971: 102) is a simpler measure than that for mean accessibility, and the indicators derived from it are highly appropriate for the study of differences in accessibility within a single province. The distribution of population is taken into account by weighting the distance values $\mathrm{d}_{\mathrm{kij}}$ by the size of population $\mathrm{h}_{\mathrm{kj}}$. The optimal site for the provincial capital is then defined as the commune centre which receives the best integral accessibility value. Since

$$
d_{k j}^{s}=\sum_{j} h_{k j} d_{k i j}
$$

the optimal centre for the province $\mathrm{k}$ is a node $\mathrm{v}_{\mathrm{kr}}$ such that

$$
\begin{aligned}
d_{k r}^{s}= & \min d_{k i}^{s} \\
& i=1,2, \cdots n_{k} .
\end{aligned}
$$

Since identification of the centre within the province which is characterized by maximal integral accessibility constitutes a solution to the minisum location problem for that province, the node $\mathrm{v}_{\mathrm{kr}}$ may be termed the median of the graph. As it is customary to search for a number $p$ of nodes within the graph at the same time, such that their combined integral accessibility is maximalized, we have a solution to the p-median problem (cf. Korpelainen \& Tykkyläinen 1978: 32).

Equations 12 and 13 entail calculation of the integral accessibility of the nodes in the graph, and consequently the median obtained is also a node. It is an interesting 
question whether the optimum solution is always to be found from among the set of nodes $\mathrm{V}$, or whether some point corresponding to an edge within the graph might not offer a better solution. It is possible, in fact, to demonstrate that the optimum solution is always to be found at one of the nodes, so that Equation 13 gives at the same time the absolute median for the graph (for proof, cf. Christofides 1975: 109, theorem 1).

In order to facilitate comparisons between the other nodes in terms of accessibility, each centre is assigned an integral accessibility value as a percentual deviation from that of the optimal centre, according to the equation

$$
\mathrm{s}_{\mathrm{ki}}=\frac{\left(\mathrm{d}_{\mathrm{ki}}^{\mathrm{s}}-\mathrm{d}_{\mathrm{kr}}^{\mathrm{s}}\right)}{\mathrm{d}_{\mathrm{kr}}^{\mathrm{s}}} \cdot 100 .
$$

The relation $\mathrm{s}_{\mathrm{ki}}=\left(\overline{\mathbf{x}}_{\mathrm{ki}}-\overline{\mathbf{x}}_{\mathrm{kr}} / \overline{\mathbf{x}}_{\mathrm{kr}}\right) \cdot 100$ also holds, in which $\overline{\mathbf{x}}_{\mathrm{kr}}=\min \overline{\mathbf{x}}_{\mathrm{ki}}$. This percentual deviation $\mathrm{s}_{\mathrm{ki}}$ enables the relative status of the different nodes in the graph, i.e. the centres in the province $\mathrm{k}$, to be examined, so that the changes in these values reflect directly the decline in integral accessibility with distance away from the optimal centre. Thus it may also be given a very simple empirical interpretation in terms of changes in the distance sum with respect to the optimal centre.

The sensitivity of the spatial structure described by the graph may be tested, simulated or predicted by associating transformation functions with the nodes or edges in the graph. In this way a variety of simulation models may be constructed by altering the weightings assigned to the centres, rendering the structure of the graph dynamic with respect to time or transforming it by means of probability functions.

An analysis is also made here of the influence of the provincial capital upon the optimal structure of the administrative region by giving $h_{k j}$ the value zero when $j$ refers to the capital. The spatial structure is also modified by interchanging the population sizes of the provincial capital and other communes, allowing for each province having $\mathrm{n}_{\mathrm{k}}$ different structures. By calculating the percentage deviation in integral accessibility for such graphs, comparisons may be obtained of the influence of the provincial capital upon changes in the accessibility of the commune centres.

\section{Accessibility and the concept of centre in} graph theory

The concept of centre in graph theory is applied in such a way as to enable the spatial structure to be studied by placing the provincial centre in the location which minimizes the maximum value for relative accessibility. The centre is thus that node which lies at the shortest distance from the most remote node in the graph. When for a province $\mathrm{k}, \mathrm{d}_{\mathrm{kj}}^{\mathrm{m}}=\max \mathrm{d}_{\mathrm{kij}}(\mathrm{j}=1,2, \cdots, \mathrm{n})$, then the centre is a node $v_{k e}$ such that $d_{k e}=$ min $d_{k i}^{m}(i=1,2, \cdots, n), d_{k e}$ may then be termed the radius of the graph.

It can be shown that there will usually be an edge $e_{k i}$ in the graph which contains a point $\mathbf{x}_{\mathrm{k}}$ which is a shorter distance away from the most remote node than is the node designated as the centre. This point $\mathbf{x}_{\mathrm{ko}}$ identified in the edge $\mathbf{e}_{\mathrm{kj}}$, which-in effect lies at the shortest possible distance from the most remote node in the graph, is termed the absolute centre of the graph. The absolute centre of a graph $\mathrm{k}$ fulfils the condition

$$
\max d\left(x_{k o}, v_{k j}\right) \leq \max d\left(x_{k}, v_{k j}\right) \text {, }
$$

$$
1 \leq \mathrm{j} \leq \mathrm{n}_{\mathrm{k}} \quad 1 \leq \mathrm{j}<\mathrm{n}_{\mathrm{k}}
$$

when $x_{k} \in G_{k}$. The absolute radius of the graph is $r\left(x_{k_{0}}\right)$ :

$$
\begin{gathered}
r\left(x_{k o}\right)=\max d\left(x_{k o}, v_{k j}\right) \\
1 \leq j \leq n_{k}
\end{gathered}
$$

An algorithm for the calculation of this is presented in Korpelainen \& Tykkyläinen (1978: 23-25).

It is also possible to weight the nodes of the graph, in which case $d\left(x_{\bar{k}}, v_{k j}\right)$ is replaced by $\mathrm{h}_{\mathrm{kj}} \mathrm{d}\left(\mathbf{x}_{\mathrm{k}}, \mathrm{v}_{\mathrm{kj}}\right)$.

The use of the concept of centre as defined in graph theory in the evaluation and planning of regional structures is justified in cases where one wisines to ensure the minimum possible transaction journey for the population of the most remote areas (cf. Seppälä 1973: 66, Kangas 1976: 6), i.e. the aim is maximum accessibility for the most remote areas. This is justified in cases where one aims to create equality between different parts of a region. Such a concept is useful not only in examining the optimum location for an administrative centre, but also in considering the location of various emergency services, although here travelling time 
would provide a better basis for optimization than distance.

The concept of centre is employed in the present work to examine the extent to which the most remote districts have been taken into consideration in arranging the spatial structure of the provincial administration. The absolute centre is not the (pareto-) optimal solution to the location problem as far as the population as a whole in concerned, however, as it is normally possible to identify a node, the median node, which represents the optimal location better in this respect than does the absolute centre.

\section{The provinces of Finland as graphs}

The material for the accessibility analysis to be presented here comprises the 11 provinces of Finland and the six proposed new provinces. Aland is excluded from this material in view of the very special nature of the terrain and the transport problems created by this. The analysis of shape treats the provinces as polygonal graphs, the borders of which are the provincial boundaries, the national boundary and the sea coasts. The diameters of these areas are measured from the most distant points on the respective boundaries.

The graphs used for the analysis of contacts and costs are composed of transport networks (Fig. 4), with the main villages of the communes as the nodes, weighted according to the populations of the communes on 31. 12. 1975 (ST $v$ 1978: table 15). Where the same locality serves as the administrative centre for two communes, e.g. in the case of the urban and rural communes of Lohja, the sum of the populations is used for the weighting. In view of the limited capacity of the computer, it was necessary to combine the communes of the province of Turku and Pori in the manner set out in the proposed review of commune boundaries in that region (see Consultative Board on Commune Boundary Revisions 1970: appended map), and the same is also done for the proposed

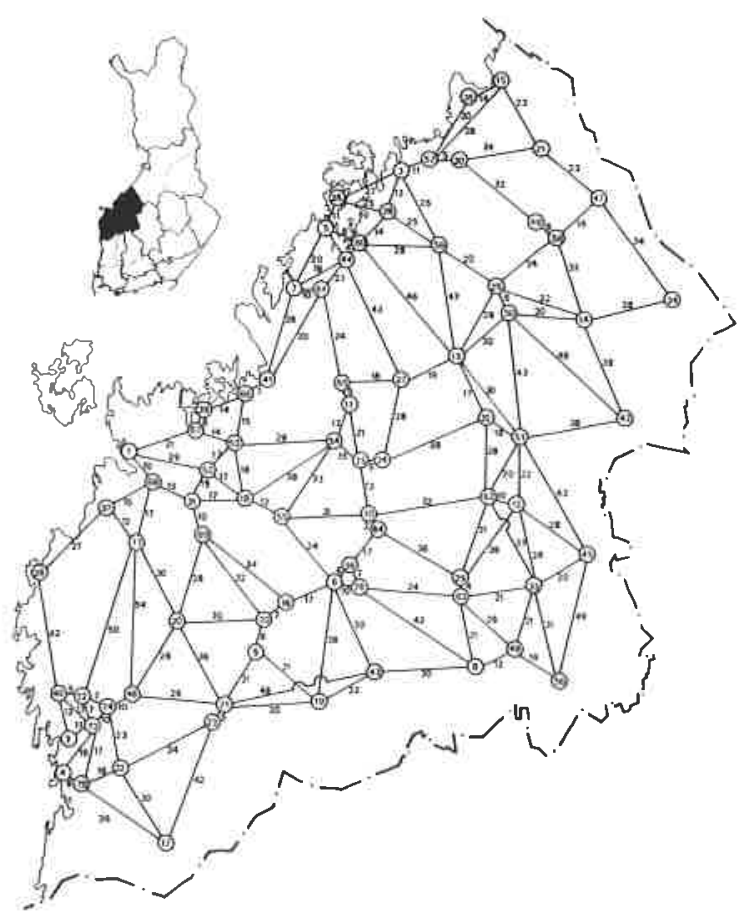

Fig. 4. Example of the basic material: graphic representation of the province of Vaasa.

new provinces of Varsinais-Suomi and Satakunta. Some of the communes in the western part of the proposed province of Pirkanmaa are similarly combined for the same reason. Although this gives rise to a certain inexactitude in the results when viewed in terms of the present communes, strict comparability is maintained between the combined communes in the analysis given here.

The edges of the graphs consist of two-lane main roads of width at least 5 metres (Road Map of Finland, sheets 1-19), and in a few cases of single-lane roads over 4 metres in width where no larger road is available between two nodes, or where one could assume the single-lane road to be of significance for communication. There are nevertheless no more than ten such cases altogether. Road junctions are also taken as nodes on the graphs where this leads to a reduction in the number of edges required. Such nodes do not affect the results in any way. The edges are weighted according to their length as indicated on the Road Map of Finland. The 
Table 1. Numbers of nodes and edges in the graphs for the provinces of Finland.

\begin{tabular}{lccr}
\hline Province & $\begin{array}{c}\text { Nodes } \\
\text { depicting } \\
\text { commune } \\
\text { centres }\end{array}$ & $\begin{array}{c}\text { Total } \\
\text { nodes }\end{array}$ & $\begin{array}{r}\text { Total } \\
\text { edges }\end{array}$ \\
\hline Uusimaa & 38 & 67 & 115 \\
Turku and Pori & 48 & 70 & 127 \\
Häme & 48 & 72 & 136 \\
Kymi & 27 & 39 & 55 \\
Mikkeli & 26 & 51 & 77 \\
Northern Karelia & 19 & 34 & 50 \\
Kuopio & 24 & 39 & 61 \\
Central Finland & 31 & 58 & 82 \\
Vaasa & 56 & 78 & 153 \\
Oulu & 52 & 78 & 130 \\
Lapland & 21 & 35 & 49 \\
Varsinais-Suomi & 25 & 38 & 65 \\
Satakunta & 18 & 22 & 36 \\
Etelä-Häme & 22 & 33 & 56 \\
Pirkanmaa & 31 & 43 & 77 \\
Northern Ostrobothnia & 42 & 60 & 97 \\
Kainuu & 10 & 11 & 17 \\
\hline
\end{tabular}

size of the graphs for the various existing and proposed provinces are detailed in Table 1.

After formation of the distance matrices, the material was checked and revised in accordance with the distance data and tables provided on the Road Map of Finland and Motorist's Road Map (1978). This was done by selecting $20-40$ items at random and checking and correcting these. The weightings of the centres were checked by summing the data for each province. The material was then examined using a set of graph theory programs (Korpelainen \& Tykkyläinen 1978), together with 14 new programs constructed for this purpose.

The work served to demonstrate that the cartographical material published by the Finnish Land Survey Board should be presented in a form in which it would be more easily adaptable for data processing than it is at present, e.g. on magnetic tape, punched tape or diskettes. Much less time would then need to be spent by the research workers themselves on the assembling, coding and input of data. A very considerable saving in time could be achieved, and such material would also lend itself to many applications of the present kind and to further research.

\section{Accessibility in the existing and proposed new provinces}

\section{Shape of the province}

The shapes of the provinces under the present system and in the proposed new devision are examined in Table 2. The province which comes closest to the optimal shape within the existing system is that of Kuopio, whose surface area amounts to $73 \%$ of that of a regular hexagon of the same diameter. Mikkeli, another entirely landlocked province, also comes close to this ideal, with a value of $63 \%$, while the worst figures are recorded for the provinces of Kymi (30\%) and Uusimaa ( $31 \%)$. The average value for the existing provinces is $53.5 \%$ (Table 2).

No substantial improvement in the shapes of the provinces seems to be achieved under the revised system. The division of the present province of Turku and Pori gives one new province, Varsinais-Suomi, which is closer to an optimal shape and one, Satakunta, which is of a less advantageous shape (Table 2), while the division of the province of Häme similarly produces that of Pirkanmaa with a higher shape coefficient and that of Southern Häme with one that is lower than before and below the mean for the whole country. The new province of Northern Ostrobothnia, comprising the northern and western parts of the present province of Oulu, is substantially smaller in area and of a less advantageous shape than its predecessor, although the maximum distance remains the same. The eastern part of the present province of Oulu, the new province of Kainuu, on the other hand, comes very close indeed to an optimum shape, comprising a land area which is $82 \%$ of that of the corresponding regular hexagon. The overall influence of the new system of provinces is very slight indeed, the proposed new provinces having a mean shape coefficient of 0.588 compared with 0.570 in the existing provinces affected by these changes.

Another approach to studying the shape of an area is to count the number of contacts with other areas, although this is not particularly helpful in the case of Finland, as most of the provinces border on either the sea or the national boundary. Only four of the 
Table 2. Indices of shape for the provinces of Finland.

\begin{tabular}{|c|c|c|}
\hline Province & $\mathrm{S}^{\prime}$ & $\begin{array}{l}\text { No. of } \\
\text { contacts }\end{array}$ \\
\hline Uusimaa & 0.31 & \\
\hline Turku and Pori & 0.50 & \\
\hline Häme & 0.60 & 6 \\
\hline Kymi & 0.30 & \\
\hline Mikkeli & 0.63 & 5 \\
\hline Northern Karelia & 0.55 & \\
\hline Kuopio & 0.73 & 4 \\
\hline Central Finland & 0.52 & 5 \\
\hline Vaasa & 0.55 & \\
\hline Oulu & 0.61 & \\
\hline Lapland & 0.58 & \\
\hline Varsinais-Suomi & 0.69 & \\
\hline Satakunta & 0.45 & \\
\hline Southern Häme & 0.51 & 7 \\
\hline Pirkanmaa & 0.69 & 4 \\
\hline Northern Ostrobothnia & 0.37 & \\
\hline Kainuu & 0.82 & \\
\hline$\overline{S^{\prime}} \quad$ (present provinces) & 0.535 & \\
\hline $\begin{array}{l}\bar{S} \text { ' (proposed provinces: values } \\
\text { for new provinces weighted } \\
\text { at } 1 / 2 \text { ) }\end{array}$ & 0.540 & \\
\hline
\end{tabular}

existing provinces, and five under the new system, are surrounded on all sides by other Finnish provinces, and no very clear example of a province which is hexagonal in shape emerges (Table 2).

The assumption of a homogeneous pattern of provinces on a euclidean plane involves a highly abstract mathematical analogy which does not take account of physical conditions, geopolitical status or the tendency for spatial concentration. The material does allow us to conclude, however, that those provinces that do not possess any sea coast or lie on the national boundary have highes indices of shape than the others. The revision in the system of provinces, on the other hand, does not improve the shapes of the administrative regions to any substantial degree.

\section{Mean and relative accessibility}

The provinces of Finland vary considerably in size, with that of Uusimaa the smallest in surface area and those of Lapland, Oulu and Vaasa by far the largest. It is thus reasonable to assume that the relative accessibility of the provincial capitals will be similar in most of the provinces, with the exception of the above large provinces and of Uusimaa, in which the majority of the population is in any case concentrated in a restricted area around the capital, Helsinki. It can also be assumed that the size of the province will affect its mean accessibility value and the standard deviation in accessibility.

The mean and standard deviation values for accessibility do in fact vary considerably from one province to another (Table 3 ), and surprisingly, it appears that accessibility is poor in some of the communes of Southern Finland. By definition, accessibility is poor, when it is below the mean $\left(d_{i j}>x ; d_{i j}>x_{k i}\right)$. There are three provinces in which twothirds of the population live in areas with an accessibility with respect to the provincial capital which is below the mean for the whole country (i.e. $d_{i j}>\bar{x}$ ), and two of these are located in the south (Table 3 ).

The province of Uusimaa stands out clearly from all the others, having particularly good figures for both mean accessibility and the standard deviation. This is due to the pronounced concentration of the population in the Helsinki area. The shape of the province, on the other hand, is anything but optimal, and very remote population centres are also to be found, the extreme example being the town of Hanko. These large internal variations in accessibility are reflected in the coefficient of variation for the accessibility values, which is very much higher than in any of the other provinces. There are nevertheless a smaller number of places with an accessibility below the mean for the whole country than in any other province (Fig. 5), and under $10 \%$ of the population live in such areas (Table 3).

The mean accessibility figure for the province of Turku and Pori is the fourth worst in the country and the standard deviation the third greatest (Table 3 ). Over a half of the people live in areas with a relative accessibility below the mean for the country as a whole, and $45.2 \%$ in the area where relative accessibility in respect of the provincial capital is better than the national mean. Relative accessibility is poor throughout the district of Satakunta, and since this area traditionally forms a separate entity (Fig. 5), the formation of a new province of Satakunta would seem to be justified. 
Table 3. Mean accessibility $(\mathrm{km})$ and its standard deviation and distribution of the population by accessibility in the provinces of Finland.

\begin{tabular}{lcccc}
\hline Province & 1 & 2 & 3 & 4 \\
\hline Uusimaa & 22.2 & 28.9 & 90.7 & 72.6 \\
Turku and Pori & 71.3 & 61.5 & 45.2 & 51.2 \\
Häme & 67.5 & 31.8 & 28.3 & 35.6 \\
Kymi & 65.5 & 46.3 & 55.9 & 55.9 \\
Mikkeli & 66.7 & 43.1 & 39.4 & 39.4 \\
Northern Karelia & 50.5 & 41.4 & 59.0 & 53.3 \\
Kuopio & 51.5 & 38.7 & 57.8 & 41.8 \\
Central Finland & 40.5 & 39.0 & 65.3 & 49.8 \\
Vaasa & 82.5 & 47.9 & 26.2 & 42.4 \\
Oulu & 98.0 & 78.8 & 35.1 & 48.8 \\
Lapland & 104.5 & 77.8 & 23.8 & 38.8 \\
Varsinais-Suomi & 25.4 & 28.4 & 80.2 & 67.8 \\
Satakunta & 30.0 & 26.2 & 61.2 & 48.4 \\
Southern Häme & 49.7 & 28.4 & 44.7 & 38.5 \\
Pirkanmaa & 26.7 & 29.9 & 72.6 & 58.7 \\
Northern Ostrobothnia & 70.6 & 67.3 & 48.3 & 51.4 \\
Kainuu & 52.1 & 43.2 & 56.6 & 56.6 \\
\hline
\end{tabular}

$1=$ mean accessibility

2 = standard deviation

$3=$ percentage of population living in areas with an accessibility relative to the provincial capital better than the mean for the whole country

$4=$ percentage of population living in areas with an accessibility relative to the provincial capital better than the mean for the province

Mean accessibility relative to the provincial capital for the whole country is 59.8 for the present provinces, and the standard deviation 48.5.

Mean accessibility in the province of Häme is poor, although the standard deviation is not great (Table 3 ). Population growth in this province has mostly taken place in centres other than the capital, Hämeenlinna, with Tampere constituting the largest centre in the province and Lahti serving as a major centre in the east. Both of these latter towns have an accessibility with respect to the provincial capital which is below the mean for the whole country (Fig. 5). The recognition of the northern part as a separate province of Pirkanmaa has been proposed on a number of occasions, but Lahti would still remain on the edge of the new province of Southern Häme.

Relative accessibility in the province of Kymi is poor, and very poor in relation to its size (Table 3 ). The population is concentrated in two regions, one following the Salpausselkä ridge and the other the valley and estuary of the Kymi river. It is the communes in the north-east that are in the worst position

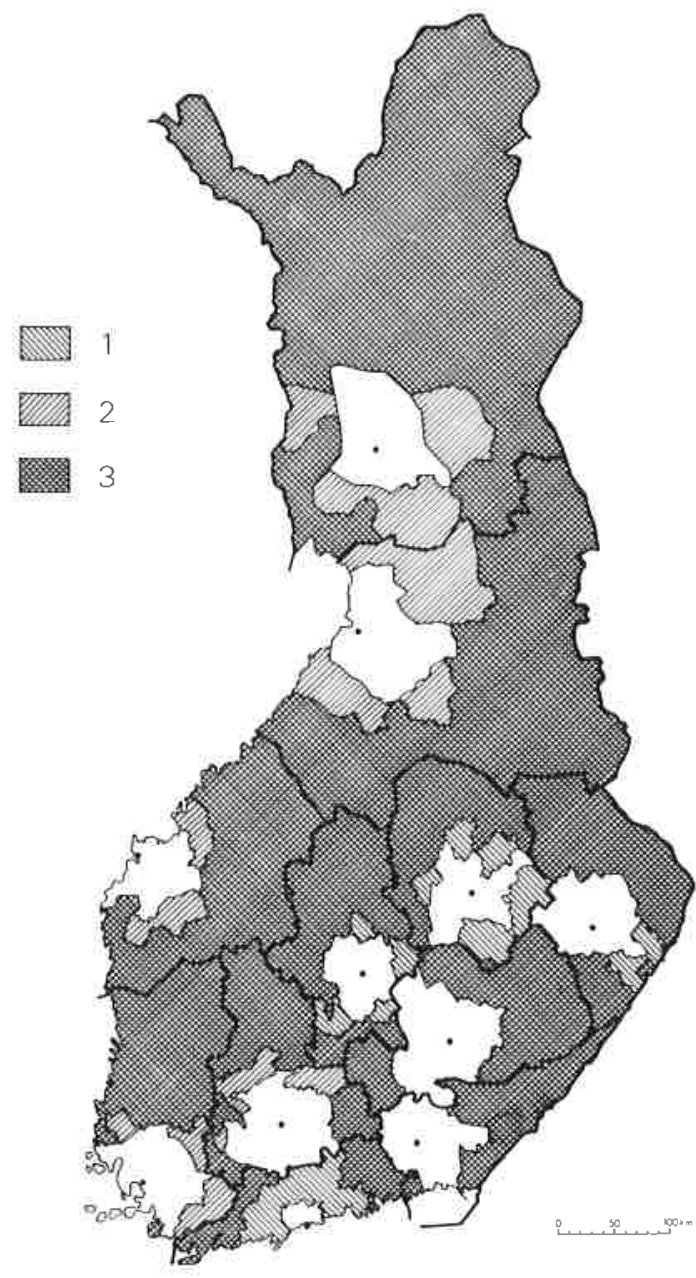

Fig. 5. Relative accessibility with respect to the provincial capital in the provinces of Finland. Relative accessibility poorer than: (1) mean for province, (2) national mean and (3) national and provincial means.

of all regarding accessibility. The matter should certainly be raised as to how the structure of this province, and the manner in which it borders onto other provinces, could be improved, although in view of the distribution of population and the proximity of the sea to the south and the national boundary in the east this would be a particularly difficult problem.

Relatively high indicator values are also assigned to the province of Mikkeli, due to the location of two large centres on the perimeter of the province, Heinola in the 
south-west and Pieksämäki in the north (Table 3). Some discussion has been entered into in the boundary review committees, but no positive measures have been proposed.

The provinces of Northern Karelia, Kuopio and Central Finland, form a relatively distinct group of their own, all being located in the interior of the country. Relative accessibility is better than the national mean for more than a half of the population in each case (Table 3 ), but is poorer in the north, and all three provinces have a mean accessibility which is better than that for the country at large and a standard deviation which is smaller. Thus the present structure of regional government can be regarded as relatively successful as far as these provinces are concerned.

Mean accessibility in the province of Vaasa is the third worst in the country, and only $26.2 \%$ of the population live in the area in which relative accessibility is better than the national mean (Table 3 ). This poor result is partly due to the fact that the provincial capital is located some distance away from the relatively densely populated region of Southern Ostrobothnia. No plans are made in any of the recent reports for any changes in the boundaries of this province, however, in spite of the fact that in addition to deficiencies in accessibility it forms somewhat heterogeneous entity in its present form as a functional and administrative region (e.g. Palomäki 1968).

As was to be expected, relative accessibility is poor in the province of Oulu (Fig. 5), in which the mean value is the second poorest in the whole country after Lapland. Even so, over a third of the population live in an area with a relative accessibility better than the national mean (Table 3), a higher proportion than in the provinces of either Vaasa or Häme, since a large proportion of the province's population is located in and around the capital, Oulu. The north-eastern, eastern and southern parts of the province are in the worst position as far as accessibility is concerned, and although it is proposed to establish a new province of Kainuu in the east, this will do nothing to improved the accessibility of services for the people of the north-east of the present province.

The province of Lapland has the worst accessibility figures of all, although the mean figure is only $6.2 \%$ worse than that for the
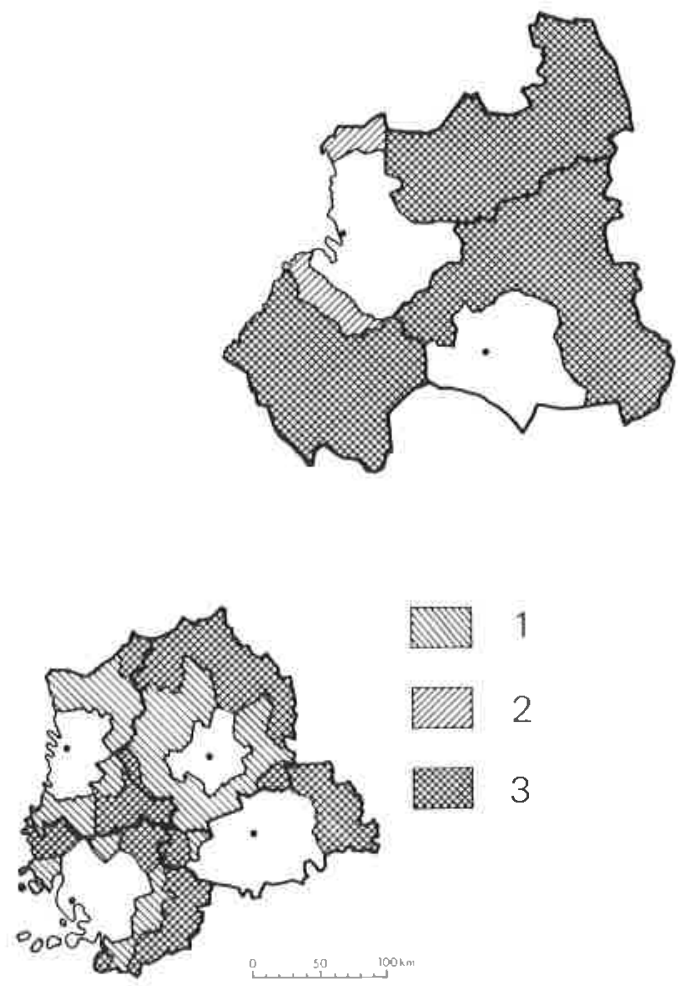

Fig. 6. Relative accessibility with respect to the provincial capital in the proposed new provinces. Relative accessibility poorer than: (1) mean for province, (2) national mean and (3) national and provincial means.

province of Oulu and $21.1 \%$ worse than for Vaasa, and the standard deviation is better than for the province of Oulu (Table 3). Accessibility is below the mean level for the country in general everywhere except in the town and rural commune of Rovaniemi, which together account for $23.8 \%$ of the population. In spite of the poor accessibility and the fact that settlement falls psychologically into three distinct regions, the size and density of the population are such that it would scarcely be functionally feasible to subdivide the region into smaller provinces.

The revision of the provincial boundaries will bring with it quite substantial changes in accessibility with respect to the provincial capitals, the mean accessibility for the country as a whole improving by $22.7 \%$, from a value of 59.8 to 46.25 . A particularly successful measure in this respect is the division of the province of Turku and Pori into two 


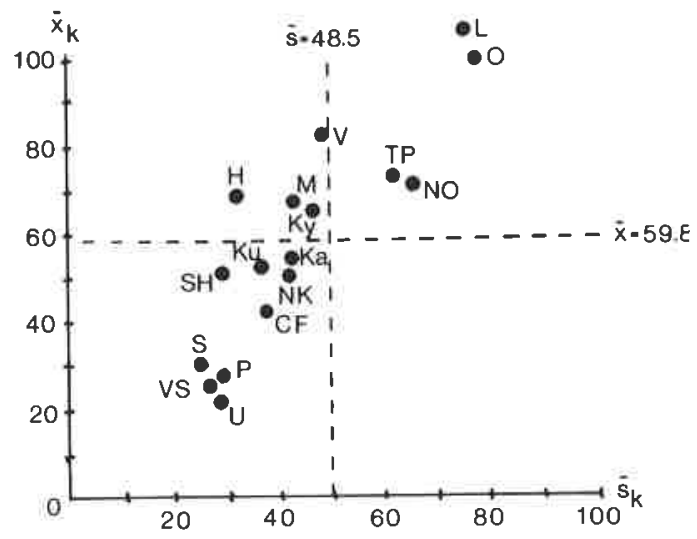

Fig. 7. Mean accessibility and standard deviation in the provinces of Finland in relation to the national means for the present provinces.

parts, Varsinais-Suomi and Satakunta (Table 3, Fig. 6), both of which have a very much better mean accessibility and standard deviation than does the present province. These two new provinces resemble Uusimaa in their accessibility structure, and are also rather similar to this province in size, although Satakunta is about $23 \%$ smaller in surface area.

The division of the province of Häme into Southern Häme and Pirkanmaa does not lead to such a great improvement in accessibility, however (Table 3), with accessibility for Southern Häme remaining rather poor in spite of the small size of the proposed new province. This may be attributed to the remote location of Lahti and the relatively dense settlement in the south of the province. Pirkanmaa, on the other hand, is more satisfactory in its structure, and is also larger in surface area than any of the other proposed new provinces in the south of the country, and larger than the existing province of Uusimaa. The successfulness of this solution is due largely to the presence of a powerful concentration of population in the new provincial capital, Tampere, although some rather less advantageous areas in terms of accessibility are to be found in the north (Fig. 6).

The division of the present province of Oulu into Northern Ostrobothnia and Kainuu leads to an improvement in accessibility for the people in the south-east and east. The new province of Kainuu approaches the present interior provinces in its surface area and accessibility values, but Northern Ostrobothnia continues to include areas of poor accessibility in the north-east and the south.

Comparison of the calculated mean accessibility indices for the proposed new provinces and their standard deviations with present mean values shows poorer than average results to be obtained in Lapland, Northern Ostrobothnia, Vaasa, Kymi and Mikkeli (Fig. 7).

\section{Optimum location and integral accessibility of the provincial capitals}

Integral accessibility depicts the accessibility of a commune centre $i$ from all the other commune centres in the province. The percentage deviation $s_{\mathrm{ki}}$ can then be used to compare the integral accessibilities of the various commune centres with that of the optimum centre for the province, the median of the graph. If this deviation $s_{k i}$ is to be used to compare different provinces the mean accessibility of the optimum centre also has to be taken into account, since the percentages as such depict integral accessibility in relation to the optimum centre of the same province. The examination of integral accessibility also takes account of the location of the population within the area, a feature which is allowed to affect the index value and the location of the optimum centre. The index values obtained are presented in Fig. 8.

The largest deviations here are to be found in the province of Uusimaa, where the heavy concentration of population in the Helsinki area causes the accessibility of the centres in the eastern and western parts of the province from all other centres to decline very sharply. This concentration of population also has the effect of defining Helsinki as the optimum centre for the province, far ahead of any possible alternatives (Fig. 8).

In view of the relatively scattered distribution of population and the poor mean accessibility index, the percentage deviation 


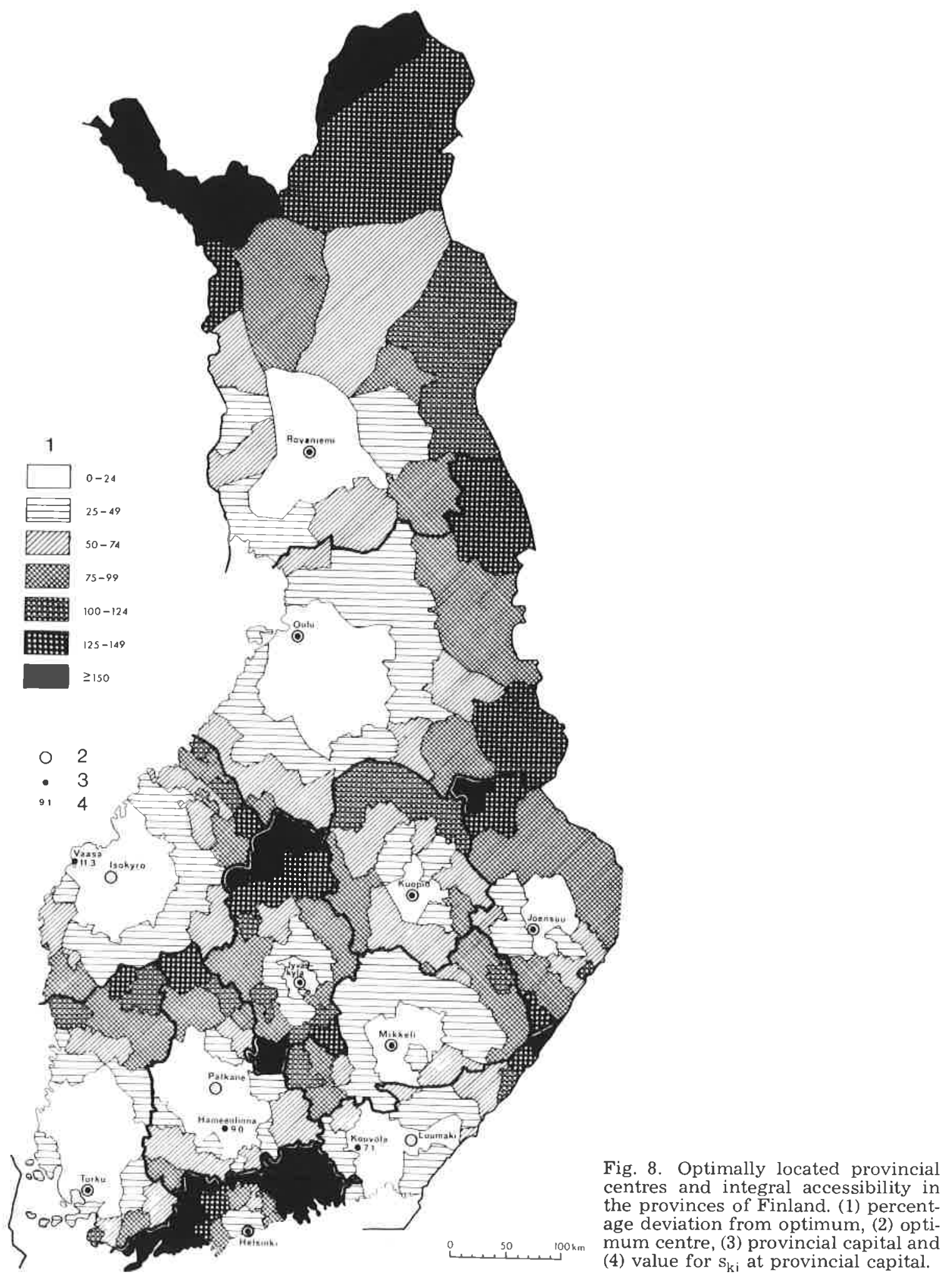


values for the province of Turku and Pori remain low, with no areas standing markedly from the others. With the majority of the population concentrated somewhat in the south of the province, the poorest accessibility figures are recorded in the north. Turku emerges as the optimum centre, although the neighbouring commune centres would be almost as good alternatives. This prime position of Turku is a consequence of the good communications in this direction. Road connections with Turku are good from most part of the province, whereas connections in an eastwest direction are poor or non-existent north of Turku up to the level of route no. 42 . The area of generally good integral accessibility is an extensive one, stretching into the southern parts of Satakunta.

The province of Häme shows good results for integral accessibility in its central area, but Hämeenlinna, the provincial capital does not emerge any longer as the optimum centre, since maximum accessibility is found in the area between Hämeenlinna and Tampere, reaching a peak at Pälkäne, which has a value $9 \%$ better than that for Hämeenlinna. Tampere would also be a reasonable candidate for the capital having the third best accessibility index after Valkeakoski. Hämeenlinna shows an integral accessibility index $8.4 \%$ poorer than that for Tampere.

Integral accessibility is good within the province of Kymi on the axes LappeenrantaKouvola and Kouvola-Kotka, the worst figures being recorded for the north-eastern part of the province. Placed alongside the relative accessibility figures, these findings mean that the communes in this area are really very isolated. Again the present provincial capital, in this case Kouvola, does not prove to be the optimum centre, lying only in second place, $7.1 \%$ worse off than the optimum, Luumäki. The spatial structure of the province of Kymi is highly problematical, the majority of the population being located on an axis running along the Salpausselkä ridge and in the valley of the Kymi river. The province is also poorly endowed in terms of shape, nor can it be shown to be a particularly rational solution as a functional unit, since it lacks an adequate population base (cf. Palomäki 1972: 11).

In the case of the province of Mikkeli the poorest indices of integral accessibility are found in the east, north-east and south-west.
The town of Mikkeli is shown to be the optimum centre, although Juva receives almost equally as good an accessibility rating.

In Northern Karelia the present provincial capital, Joensuu, proves to be the optimum centre, while the northern and southern parts are in the weakest position, as might be expected, and also the commune of Värtsilä.

The area of poorest integral accessibility in the province of Kuopio lies in the north, while the capital, the town of Kuopio, emerges as the optimum centre.

Central Finland, which was shown to be one of the best provinces in the country, alongside Northern Karelia and Kuopio, as far as mean accessibility and its standard deviation was concerned, nevertheless has areas of poor integral accessibility, especially in the north, and also to some extent in the south of the province. The provincial capital, Jyväskylä, proves to be the optimum centre according to the present calculations.

Integral accessibility in the province of Vaasa is poorest in the north and north-east, and also in the south-western corner, and since $\overline{\mathbf{x}}_{\mathrm{k}(\mathrm{opt})}$ is relatively high, the communes close to the southern boundary of the province of Oulu are particularly weak in both relative and integral accessibility. At the same time, the present provincial capital, Vaasa itself, is not in the optimum location for the present areal structure, falling $11.3 \%$ short of the integral accessibility figure for the optimum centre, Isokyrö, and also being surpassed by Lapua, $3.8 \%$ below Isokyrö, and Seinäjoki, $4.7 \%$ below.

Integral accessibility in the province of Oulu is poorest in the extreme north-east and south-east, with the southernmost areas of all also relatively badly off. The provincial capital, Oulu, is shown by the calculations to be in the optimal position, and an extensive area with good accessibility extends southeastwards from this town.

Within the province of Lapland it is only to be expected that the extreme north will constitute an area of poor accessibility, and with the population concentrated in the south of the province the optimum centre is clearly the present capital, Rovaniemi.

The revision of the provincial boundaries brings with it considerable changes in integral accessibility. All the peripheral areas in the new province of Varsinais-Suomi now seem to be in a similar position (Fig. 9), 


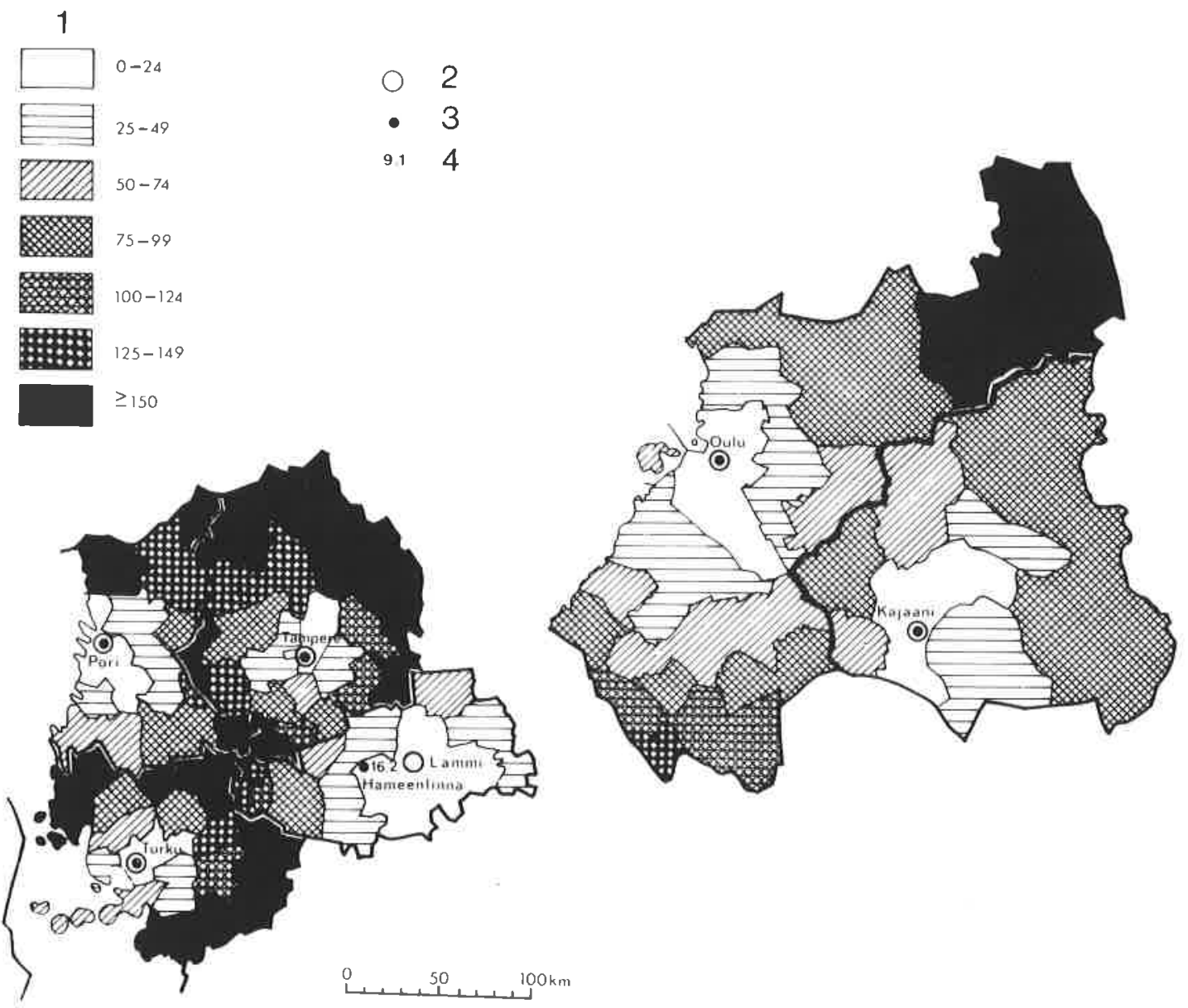

Fig. 9. Optimally located provincial centres and integral accessibility in the proposed new provinces. (1) percentage deviation from optimum, (2) optimum centre, (3) provincial capital and (4) value for $\mathrm{s}_{\mathrm{ki}}$ at provincial capital.

and the relative accentuation of the role of Turku in the spatial structure gives rise to fairly large percentage deviations for these more remote areas, although in absolute terms, and compared with the values for other parts of the country, accessibility is good throughout the province. Similarly the mean accessibility value for Varsinais-Suomi is very much better than that for the existing province of Turku and Pori. The optimum centre for the new province is quite clearly Turku.

The new province of Satakunta has its weakest accessibility ratings in the north and south-east. The optimum centre is shown to be Pori, and good integral accessibility is also recorded in the communes of the Kokemäki river valley.

Integral accessibility in the new province of Southern Häme is poorest in the west, largely due to the relatively powerful aggregation of population in the Lahti area. Hämeenlinna does not emerge as the optimum centre, being surpassed in accessibility values by the areas to the east. The value for Hämeenlinna is as much as $16.2 \%$ poorer than that for the optimum centre, Lammi, and $14.5 \%$ poorer than Lahti. Hämeenlinna thus represents a bad choice of provincial capital from the point of accessibility, while with its poor 
mean accessibility, the whole structure of Southern Häme would seem somewhat incoherent.

Within the proposed province of Pirkanmaa good integral accessibility is to be found in a rather limited area around Tampere, with very much weaker ratings given for the northern and north-eastern districts. Mean accessibility in the province as a whole is nevertheless good, due chiefly to the size of Tampere itself and to the location of the population largely in the southern parts of the province. The optimum centre is Tampere, and the province as a whole may be regarded as a relatively successful spatial structure.

The division of the province of Oulu into Northern Ostrobothnia and Kainuu leads to an improvement in conditions in Kainuu in particular. The proposed province has a sound accessibility structure, as was also seen from its mean accessibility and standard deviation figures. No steep decline in integral accessibility is found on the margins of the province, and the planned provincial capital, Kajaani, emerges as the optimum centre.

Northern Ostrobothnia, on the other hand, proves a rather unsatisfactory province both in its shape and in its accessibility ratings. Integral accessibility is poorest of all in the north-east, but bad areas are also to be found in the south. Since the mean accessibility for the province as a whole is also poor, the large percentage deviations in these marginal areas imply very low standards of accessibility. The worst commune of all in integral accessibility, Kuusamo, is indeed closer to Rovaniemi than it is to either Oulu or Kajaani. The optimum centre for Northern Ostrobothnia is shown in the analysis to be Oulu, and since p-median analysis on the data for the present province of Oulu showed the two most suitable centres to be Oulu and Kajaani, the choice of capitals for both of the new provinces would seem to be a reasonable one.

With certain outstanding exceptions, integral accessibility over the country as a whole varied in a manner somewhat similar to that noted for relative accessibility. The greatest variations within a single province were noted in Uusimaa, due primarily to the heavy concentration of population in the Helsinki area, and the second largest variation in Lapland. High percentage deviations were also recorded for the northern parts of Central Finland and the north-eastern corner of the province of Kymi. The 'handicap' imposed by poor accessibility is also more than double the optimal value in the cases of the northern and south-eastern parts of the province of Turku and Pori, the northern parts of Häme, the north-eastern and north-western areas of Mikkeli, the northern and southern parts of Northern Karelia, the northern districts of the provinces of Vaasa and Kuopio and the north-eastern and south-eastern extremes of the province of Oulu.

Among the proposed new provinces, those of Varsinais-Suomi and Pirkanmaa are constructed around major population centres, implying large internal variations in integral accessibility. Major deviations from the optimum values are to be seen on the margins of Varsinais-Suomi and in the northern parts of Pirkanmaa and Satakunta. Only relatively minor variations in integral accessibility are recorded in Southern Häme, a feature indicative in this case of a highly dispersed spatial structure.

The division of the province of Oulu into Northern Ostrobothnia and Kainuu gives rise to larger percentage deviations in the northeastern and southern parts of Northern Ostrobothnia than these areas showed when examined in the framework of the existing provincial structure. Variations in integral accessibility within the new province of Kainuu are small.

The results of this analysis proved to be better than had been expected as far as the location of the present provincial capitals was concerned, with as many as eight out of the ten provinces studied having their capital at the calculated optimal location. Better alternatives can be suggested only in the case of the provinces of Vaasa, Häme and Kymi, two towns, Lapua and Seinäjoki, emerging as more accessible centres than Vaasa, and similarly two, Tampere and Valkeakoski, as more accessible than Hämeenlinna.

Among the proposed new provinces, Southern Häme may again be said to offer better alternatives for an administrative centre than Hämeenlinna, Lahti in particular being in a more accessible location. The choice of provincial capital appears to be a 
successful one as far as accessibility is concerned in all the other instances.

The deviations $\mathrm{s}_{\mathrm{ki}}$ are indicative of the relative positions of the other centres with respect to that which proves to be the centre of optimal accessibility in the province, and their values are therefore comparable only within the one province. In spite of the largely optimal location of the present provincial capitals, however, major discrepancies in mean accessibility still remain between the provinces. Even so, the practically optimal location of the present administrative centres suggests that accessibility in the weaker provinces cannot be improved simply by transfering such functions to an alternative centre. This can only be recommended in the case of the provinces of Vaasa and Häme and the proposed province of Southern Häme, and even then the improvement would not be particularly great.

\section{Effect of the provincial capital upon integral accessibility}

Since with the exceptions of the provinces of Häme and Kymi the provincial capitals are always among the largest towns in the province, it also becomes important to examine the extent to which these concentrations of population influence the process of determining the optimal location for the centre. It is possible to eliminate the effects of these centres by defining them in the graph as commune centres having no population. Since the distance matrix $D_{k}$ and the population vector $h_{k}$ are defined as having the index value $\mathrm{k}=1$ in the case of the provincial capital, the calculations based on Equations 12,13 and 14 are now carried out with $\mathrm{h}_{\mathrm{kl}}=0 \forall \mathrm{k}$. The results are affected somewhat by what areas are regarded as belonging to the provincial capital. This is limited here to the actual urban commune which constitutes the capital itself. Since the population of this commune alone is large compared with that of the surrounding communes, it is regarded here as sufficient to study the effects of just this administrative unit upon accessibility.

With the population of the present provincial capitals eliminated in this way, only two of the existing provinces can now be shown to have an optimally located capital, namely Northern Karelia and Central Finland (Fig. 10). The greatest deviation from the current situation is found in the case of Vaasa, which proves to be a $30 \%$ poorer alternative than Lapua as the centre for its province (Fig. 10). Similarly the centre for the province of Turku and Pori shifts some distance away from Turku, to Eura, once the population of Turku itself is excluded from the analysis.

In the case of the other provinces shown in the analyses above to have their capital in a non-optimal location, Häme and Kymi, elimination of the effect of the capital itself serves to accentuate this impression. Thus the deviation of Hämeenlinna from the optimal value, that for Tampere, increases from $9.0 \%$ to $17.4 \%$, and that of Kouvola from the calculated centre, Luumäki, from $7.1 \%$ to $15.2 \%$.

Among the other provinces, the optimum centre for Uusimaa is now shown to be Vantaa, with Helsinki registering a $9.5 \%$ poorer accessibility rating, while the most accessible centre for the province of Mikkeli shifts to Juva, with Mikkeli itself deviating from this value by $7.5 \%$, and that for the province of Kuopio moves northwards to Sillinjärvi. The optimum centre for the province of Oulu is now Liminka, with Oulu $4.2 \%$ behind, and that for Lapland the commune of Keminmaa, by a margin of $1.8 \%$ from Rovaniemi.

Elimination of the population of the centres proposed for the new provinces under consideration leads to a change in the locus of optimum accessibility in all cases except two, Varsinais-Suomi and Pirkanmaa (Fig. 11). The centre for Satakunta moves from Pori to Nakkila, which surpasses the former in accessibility by $9.1 \%$, while Lahti is confirmed as the most accessible centre in Southern Häme, Hämeenlinna showing a deviation of as much as $36.9 \%$. The optimum centre for Northern Ostrobothnia shifts from Oulu to Liminka, by a margin of $8.0 \%$, and Kajaani emerges as a $14.8 \%$ poorer solution as the centre for Kainuu than is Ristijärvi.

A general assessment of the changes in accessibility brought about by the elimination of the population of the provincial capital from the calculations suggests these these are minor in extent. In theory such a measure should lead to a marked fall in the integral accessibility index for this centre and should lead to a substantial shift in the position 
Fig. 10, Optimally located provincial centres and integral accessibility in the provinces of Finland with the population of the present provincial capital excluded from the model. (1) percentage deviation from optimum, (2) optimum centre, (3) provincial capital and (4) value for $S_{\mathrm{ki}}$ at provincial capital.

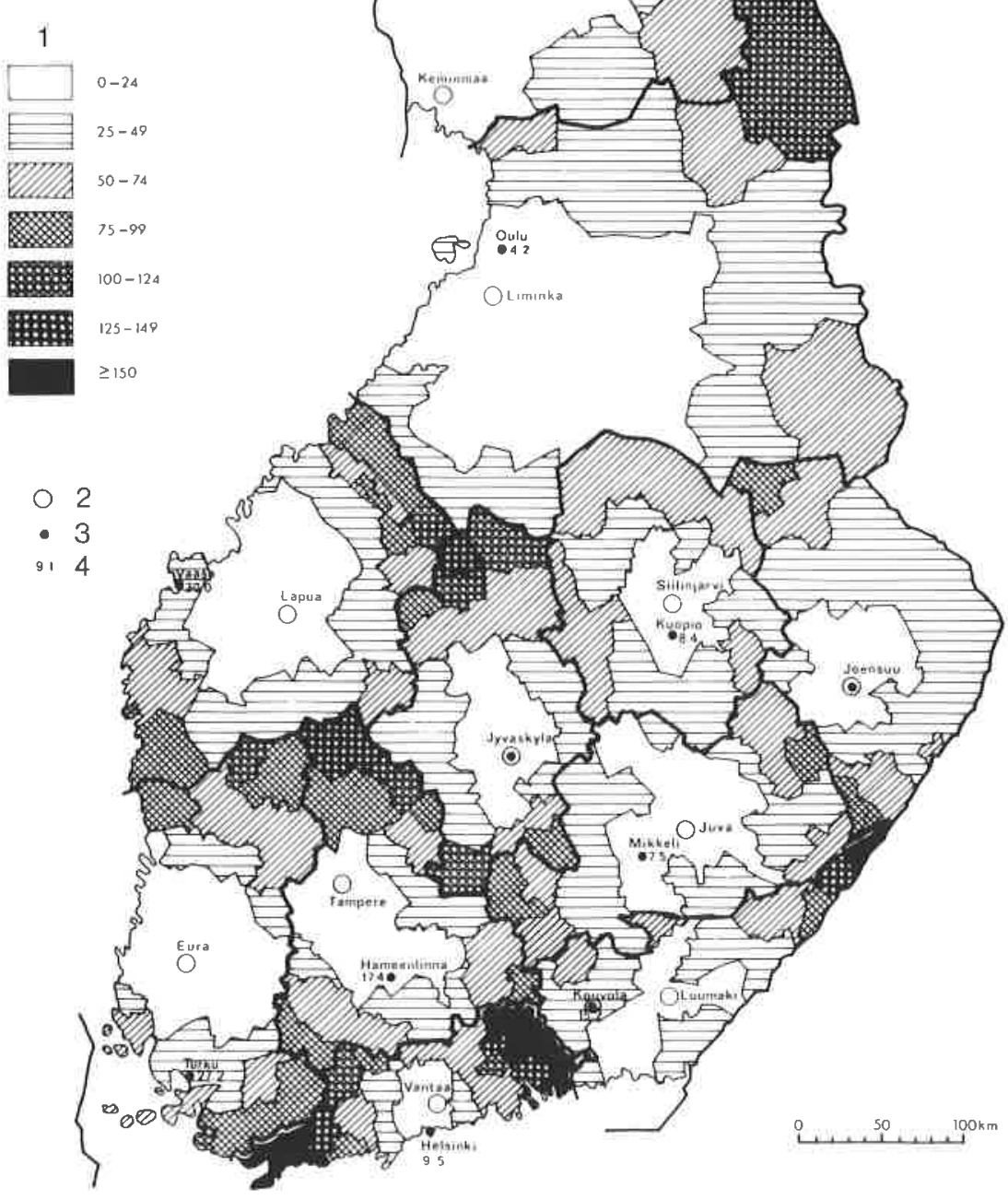




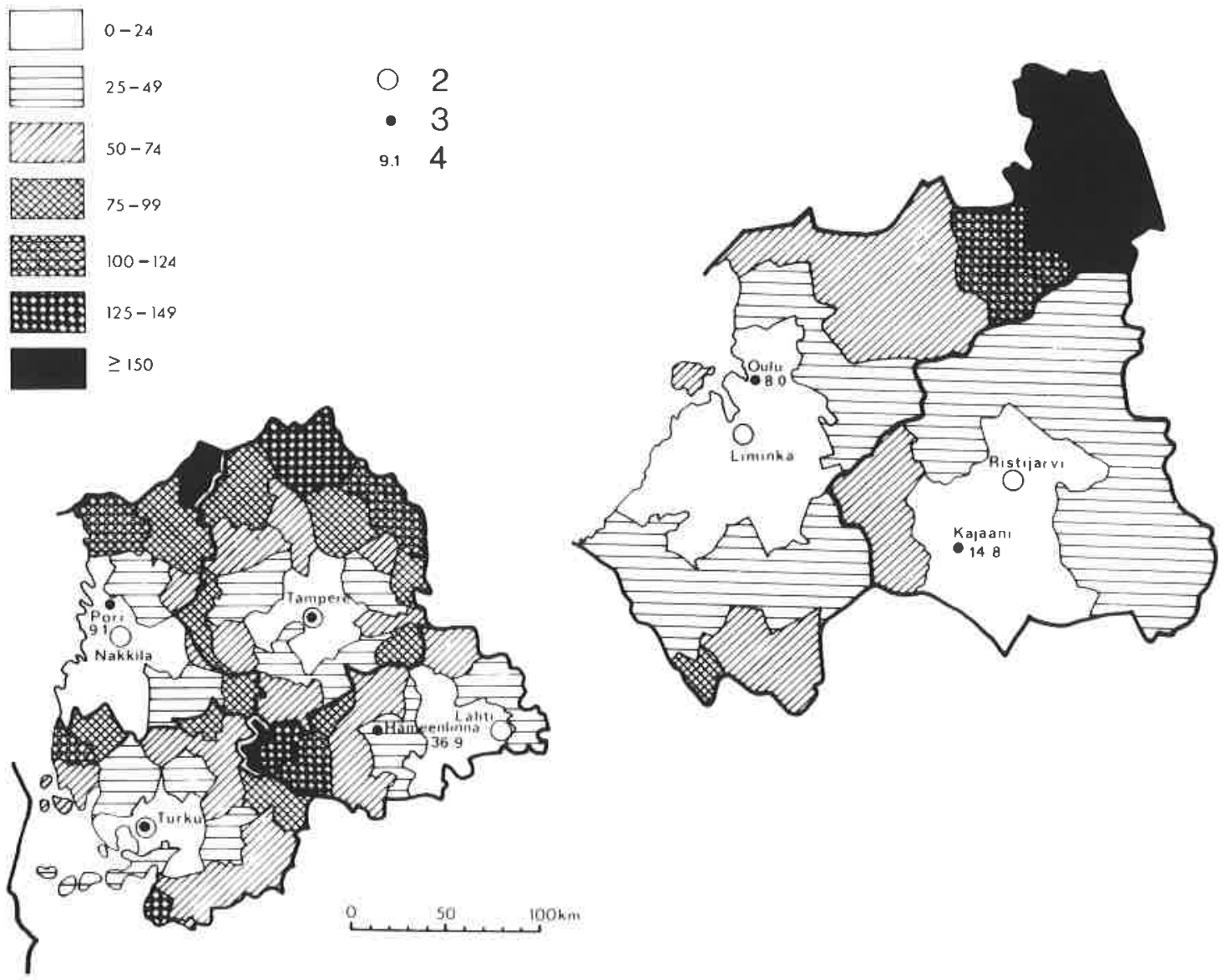

Fig. 11. Optimally located provincial centres and integral accessibility in the proposed new provinces with the population of the present and planned provincial capitals excluded from the model. (1) percentage deviation from optimum, (2) optimum centre, (3) provincial capital and (4) value for $\mathrm{s}_{\mathrm{ki}}$ at provincial capital.

of the optimum centre. This is not the case, however. It seems, in fact, that in spite of generally being the largest town in the province in terms of population, the capital does not itself exercise any substantial influence on the accessibility values recorded.

The sensitivity of the optimum centre can also be tested by varying the location of the capital within the province. For this purpose the populations of the actual capital and a centre $\mathbf{i}$ are interchanged, and each value for the percentage deviation $s_{k i}(i=2,3, \ldots$, $n_{k}$ ) is calculated for this altered structure, the corresponding value $s_{k l}$ for the capital still following the real structure. This gives an analysis in which there are $n_{k}$ different spatial structures, out of which $n_{k}=1$ describes the actual structure. The model is a hypothetical one and entirely divorced from the real world, but will serve well to show the relative permanence of the spatial structure.

The results suggest that the percentage deviations do not vary very greatly from those obtained earlier (Fig. 12, 13). The structure of the network of centres is relatively unchanged, and it seems that even quite large alterations in population are incapable of 
Fig. 12. Optimally located provincial centres and integral accessibility in the provinces of Finland given altertive spatial structures. (1) percentage deviation from optimum, (2) optimum centre, (3) provincial capital and (4) value for ski at provincial capital.

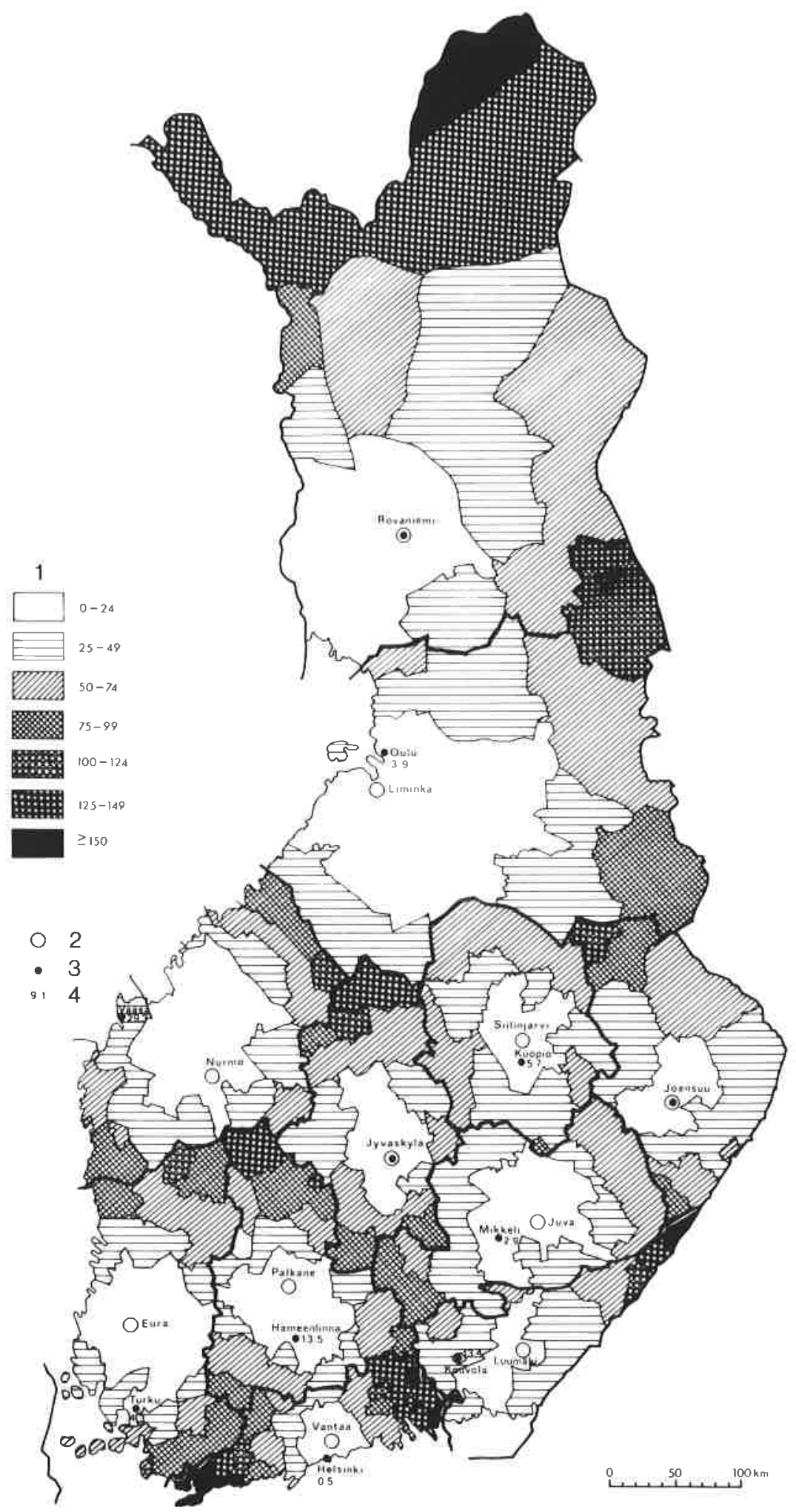


1

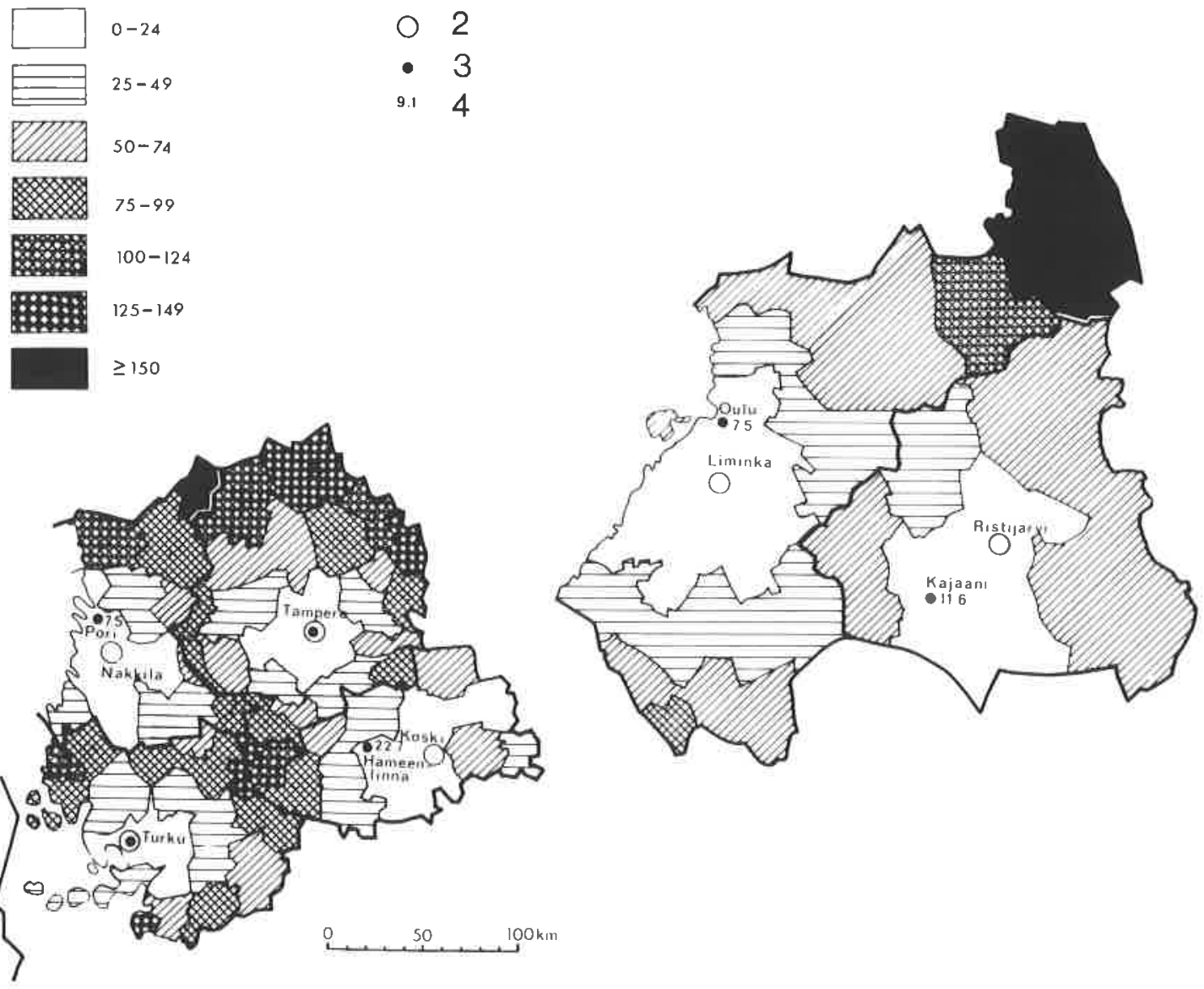

Fig. 13. Optimally located provincial centres and integral accessibility in the proposed new provinces given alternative spatial structures. (1) percentage deviation from optimum, (2) optimum centre, (3) provincial capital and (4) value for $\mathrm{s}_{\mathrm{ki}}$ at provincial capital.

having any appreciable effect upon accessibility, the pattern for which is basically similar throughout.

Thus both the elimination of the population of the provincial capital and variation of the spatial structure indicate that integral accessibility will remain practically unchanged and no particularly significant alterations in the optimal structure of centres occur compared with the existing accessibility structure. Consequently the analysis of accessibility and the definition of the optimum centres may be regarded as reflecting relatively permanent phenomena, the present spatial structure still being reflected in accessibility and the relative accessibility status of the various centres even after major rearrangements in the population. The present provincial capitals exercise little influence on the spatial structure of accessibility. From the point of view of accessibility these capitals are located in practically an optimal manner, and the population of the province is usually organized so as to give a higher density close to the capital than elsewhere, which in turn speaks for the optimal location of the present capitals. 
Fig. 14. Maximum distances from the provincial capitals and alternative centres required to minimize these distances. (1) optimum centre, (2) commune centre, (3) percentage from optimum, (4) maximum distance from provincial capital and (5) minimized maximum distance.

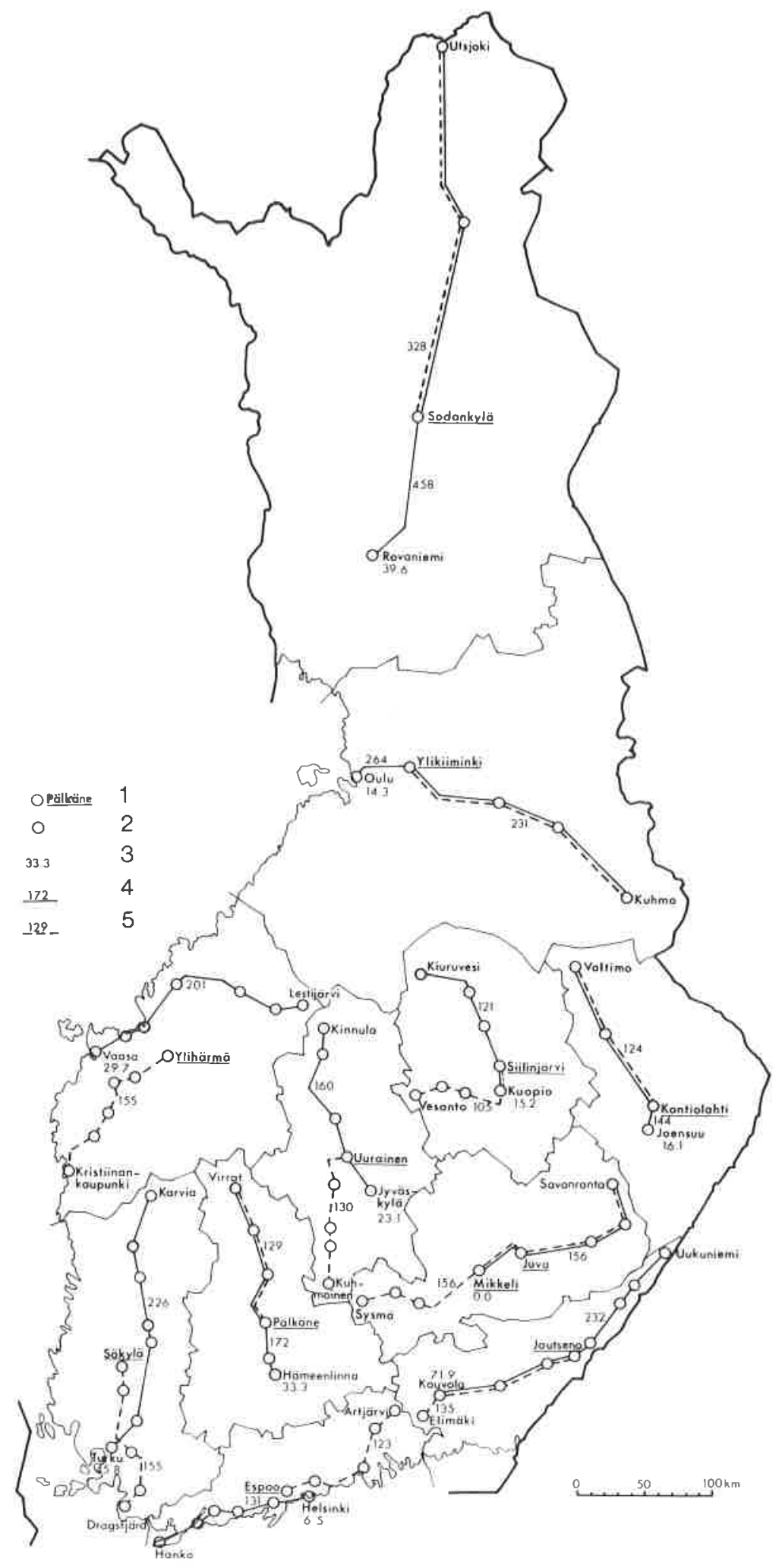




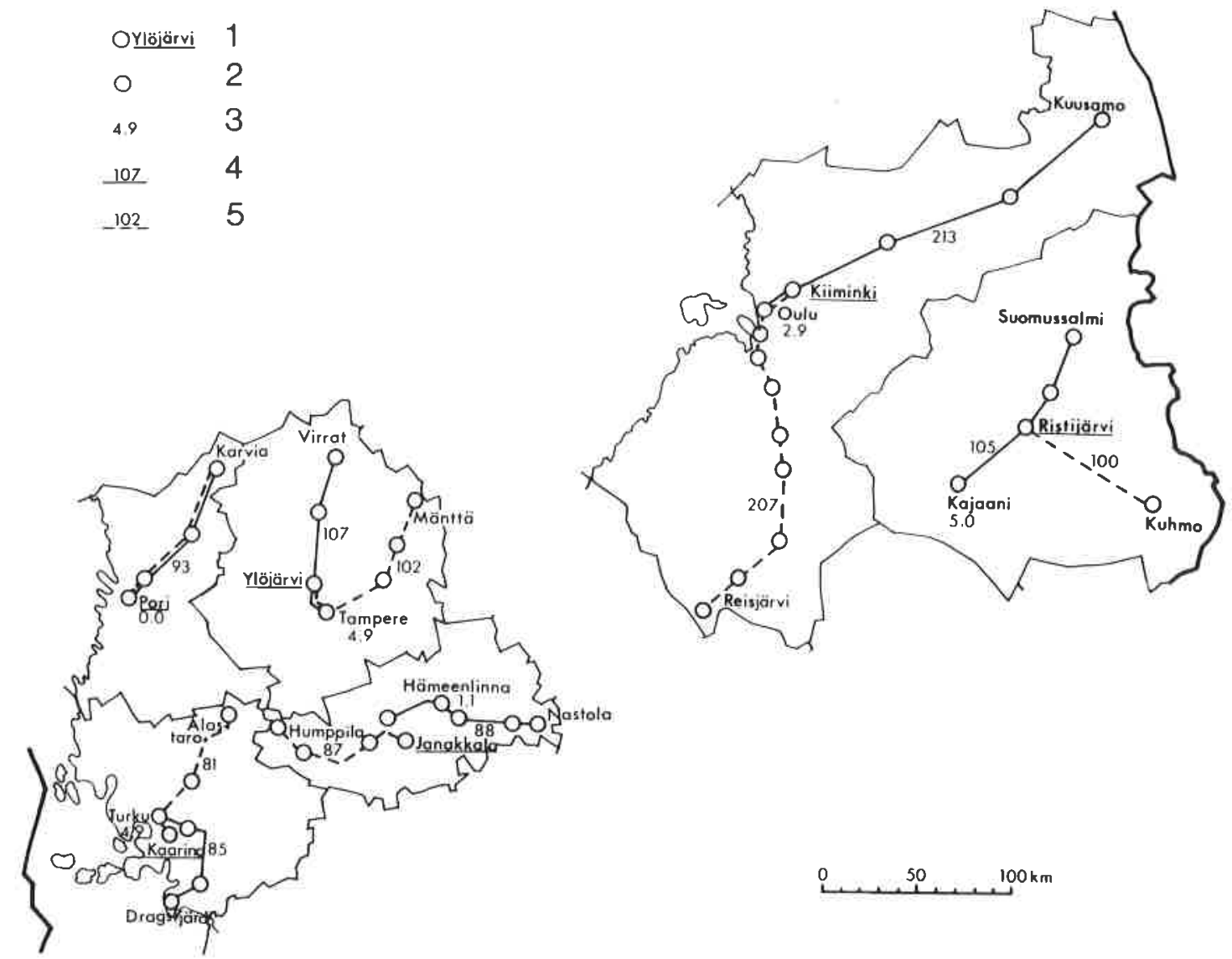

Fig. 15. Maximum distances from the capitals of the proposed new provinces and alternative centres required to minimize these distances. (1) optimum centre, (2) commune centre, (3) percentage deviation from optimum, (4) maximum distance from provincial capital and (5) minimized maximum distance.

\section{Maximum distance as a criterion for accessibility}

It is also reasonable to approach the question of accessibility as a problem of maximizing the accessibility of the most remote parts of the areas concerned. One means of achieving this, as set out in equation 15 , is by minimizing the maximum distance, a procedure known in graph theory as the minimax location problem. The empirical results are depicted in Fig. 14 and 15, in which the optimum centre is taken to be that which has the minimum value for its maximum distance from any other centre, even though an algorithm based on the absolute centre theorem could point to a better centre on some edge in the graph.
Definition of the absolute centre does not, in fact, alter the results to any appreciable extent (see data on absolute centres in Table 4). Quite considerable differences are to be seen, however, between the centres identified here and those defined by reference to integral accessibility. Examined in terms of commune centres, only the province of Mikkeli can be shown to have its capital located correctly according to the maximum distance criterion, although Juva would give an equally good result (Fig. 14).

The province of Lapland is the worst off in respect of maximum distance on an absolute scale, the most remote of the commune centres being situated as much as 458 kilometres from the provincial capital, a distance which could be reduced to $328 \mathrm{~km}$ by moving 
Table 4. Absolute centres for the present and proposed new provinces of Finland, to an accuracy of $\pm 1.5 \mathrm{~km}$. The absolute centre named in the table is the locality situated closest to the absolute centre point given by the algorithm.

\begin{tabular}{lcll}
\hline Province & $\begin{array}{c}\text { Absolute } \\
\text { radius }\end{array}$ & Locality & Commune \\
\hline Uusimaa & 119 & Matinkylä & $\begin{array}{c}\text { Espoo } \\
\text { Turku and Pori }\end{array}$ \\
Häme & 149 & Vampula & Pälkäne \\
Kymi & 126 & Epaala & Joutseno \\
Mikkeli & 132 & Ahvenlampi & Juva \\
Northern Karelia & 134 & Kilpola & Kontiolahti \\
Kuopio & 118 & Varparanta & Siilinjärvi \\
Central Finland & 102 & Kasurila & Uurainen \\
Vaasa & 128 & Kutula & Kauhava \\
Oulu & 149 & Roppi & Vaala \\
Lapland & 218 & Paatinjärvi & Sodankylä \\
Varsinais-Suomi & 301 & Mataraselkä & Lieto \\
Satakunta & 79 & Suopohja & Pori \\
& 90 & Toejoki & Kullaa \\
Southern Häme & 90 & Sammaljärvi & Hämeenlinna \\
Pirkanmaa & 83 & Kruununmylly & Tampere \\
Northern Ostrobothnia & 96 & Nurmi & Kiiminki \\
Kainuu & 202 & Välikylä & Ristijärvi \\
\hline
\end{tabular}

the capital to Sodankylä. In percentual terms the province of Kymi is in the worst position, Uukuniemi being located $232 \mathrm{~km}$ from Kouvola, whereas the maximum distance, even within the present boundaries of the province, could be reduced to $135 \mathrm{~km}$, an improvement of $41.8 \%$. Other essentially non-optimal structures are to be found in the provinces of Turku and Pori, Häme and Vaasa.

The same method shows accessibility in the proposed new provinces to be extremely good (Fig. 15). The planned provincial capital for Satakunta, Pori, also proves to be the calculated optimum centre, and the optimum occurs in communes adjacent to the proposed capital in all the other cases except for Kainuu. It is notable that the percentage difference in maximum distance from the capital and the optimum centre is never very great in these new provinces, the highest deviation, in Kainuu, being a matter of $5 \%$.

The existing provinces of Kymi, Turku and Pori, Lapland, Häme and Vaasa are thus shown to have the poorest spatial structure with respect to the maximum distance criterion, the situation being particularly bad in Kymi. The choice of administrative centre is shown to be practically the optimal one in all of the proposed new provinces, however, ensuring maximum accessibility to the centre for the inhabitants of the remotest areas, given the provincial boundaries as laid down in the proposals. Although the results point to fairly large deviations from the optimum, especially in the existing provinces, these nevertheless operate in the same direction as those obtained using the other measures of accessibility. Even so, the deviations are greater than those found on the criterion of integral accessibility, enabling us to conclude that the provincial centres are located in a more advantageous manner in respect of the population in general than they are in respect of the inhabitants of the most remote areas.

\section{Conclusions}

\section{Accessibility findings}

The results shed a reasonably favourable light upon the regional organization of provincial administration in Finland. Its regional structure is close to the optimum when examined against the assumption that it is organized on the basis of the location of the provincial capital or within the frame- 
work of the existing provincial boundaries, while some improvement in the direction of the optimal situation can be demonstrated in the plans for revising the system of provinces. This general impression is naturally partly a product of the initial assumptions, but the results may be regarded as sufficiently unambiguous that, bearing in mind these assumptions, they may be generalized to give conclusions testifying to a good correspondence between the present regional structure of provincial administration and the optimum such structure obtainable with the given number of provinces.

It is the provinces in the interior of the country that come nearest to the optimum shape, the best being Kuopio and Mikkeli, and the least successful Kymi and Uusimaa, both of which have their boundaries determined by the sea coast in the south and the ridge of Salpausselkä in the north. Kainuu is by far the most satisfactory in shape of all the proposed new provinces, while the least satisfactory is Northern Ostrobothnia, which also contains a number of regions which differ substantially in character.

Mean accessibility with respect to the provincial capital and the standard deviation in this accessibility are below the mean for the whole country in the provinces of Lapland, Oulu, Turku and Pori, Vaasa, Kymi, Mikkeli and Häme. When these results are related to the size of the province and account is taken of the possibilities and plans for improvement, it becomes clear that special efforts to improve accessibility should be made in the case of the provinces of Oulu, Vaasa and Häme.

The proposed division of the province of Turku and Pori into Varsinais-Suomi and Satakunta would imply a substantial increase in accessibility in the area, and similar values would also be achieved in the new province of Pirkanmaa, coming close to those now obtained in Uusimaa. The accessibility ratings achieved for the new province of Kainuu are also good in relation to the size and population structure of this region, but poor results are obtained for both Southern Häme and Northern Ostrobothnia.

The proposed changes in the provincial boundaries can be regarded as fairly successful as far as accessibility is concerned, although the solution for Southern Häme would seem to represent in part a conflict between the development of spatial structures and the traditional system of administrative provinces which the recommendations for revision have still failed to resolve. The formation of such a province in the southern part of the existing province of Häme and the retention of Hämeenlinna as its administrative centre may be looked on as a retrograde step, an attempt to maintain the status of the town in spite of the rapid development of new spatial structures in the region.

The creation of provinces of Satakunta, Pirkanmaa, Kainuu and Varsinais-Suomi, has been proposed in various connections for some decades, and in certain cases even for some centuries, and these areal units would seem to correspond well with the subjective opinions of the inhabitants. They will also lead to considerable improvements in accessibility to a provincial capital.

The proposals for a new province of Central Ostrobothnia, on the other hand, would again represent a conflict between boundary revision and the factors of accessibility and regional identity. No successful division of the area into provinces can be found as far as accessibility is concerned either within the existing system or after the proposed revisions. No plans have yet been produced which would solve this problem and give improved accessibility in the region, and so the present situation is likely to prevail for some time.

The location of the provincial capitals both at the present time and in the future proposals corresponds surprisingly well with the optimal structure, although there are certain provinces in which poor values are obtained for mean accessibility and its standard deviation, and in these the provincial centres are either located in a non-optimal manner, or else their permanence is not so convincing as elsewhere. An unsatisfactorily located centre will naturally tend to reduce accessibility generally. Most of these cases are the outcome of the history of the area concerned, and for this reason it has not proved possible to move the capital to a centre which corresponds better to the actual spatial structure. This is particularly true in the case of Hämeenlinna, and also partially so with Vaasa.

With the exception of Southern Häme, the 
new provinces have their capitals more satisfactorily located than do the present ones.

The tests for the permanence of the spatial structures show the provincial capitals to be located in a relatively advantageous manner even when their own populations are excluded from the calculations. Radical changes in spatial structure would be needed before their location could be said to be obviously non-optimal.

The existing spatial structure may be regarded as supporting the present system of administrative centres in the majority of the provinces. Although an attempt is obviously made to locate the provincial capitals in the optimum manner with respect to accessibility, it is also to be expected that, with certain exceptions, future developments in the spatial structure will serve only to emphasize the status of the capitals as the optimal centres.

The results also draw attention to those areas which are particularly remote from their provincial capitals, or which experience poor accessibility to other parts of the same province. The fact that the deviations of these areas from the optimal values are greater when calculated according to the minimax location concept than they are under the minisum location concept suggests that the centres are better located with respect to the population as a whole than they are with respect to the population of the remoter areas, that is, they are determined by the overall advantage of the population, with the principle of equality taking second place. This property is nevertheless not so pronounced in the proposed new provinces than it is in the existing ones. Since the new system reduces considerably the standard deviation in the accessibility, the boundary revisions can be taken to entail increased equality of accessibility. The coefficients of variation for the new provinces are still high, however, indicating large internal differences in accessibility even in these cases, although this is most commonly due to the high populations of the new provincial capitals.

Accessibility problems are to be found in the south of the country as well as the north, as is also the case with problems in the location of provincial capitals. In the south in particular, this can usually be interpreted in terms of some form of conflict between historical development and administrative organization, in which boundary revisions and other areal measures are unable to keep up with the real changes in spatial structure. The revisions now proposed represent an obvious improvement in accessibility, but even these adjustments carry their own historical burden. Examination of the proposals for revisions and the statements issued concerning these shows a clear tendency for the people in general and their democratically elected organizations to favour the existing boundaries and administrative practices. It may be that the advantages in accessibility are thought to be small by comparison with any change in old administrative traditions or feelings of regional or provincial identity which have built up over the years. Admittedly it seems that precisely those areas in which accessibility is poor are the ones for which most proposals for revision have been put forward, but it is also true that no action has been taken on the majority of these proposals.

\section{Methodological evaluation}

Research on the regional structure of provincial administration, and of administration on the regional level in general, has largely relied on the results and methods contained in the work of the Commercial Research Institute (LTT 1967). In this sense, the present application of graph theory offers a supplement to the traditional approach, and one which complements it in basing the evaluation of the spatial structure of administration on an analysis of accessibility. It therefore contains within it some theoretical and methodological contributions towards the study and planning of the spatial organization of human activity.

The theoretical starting-point for the work is a highly formal one in which the postulates of graph theory form a model depicting the optimum structure with the constraints specified. The model is an abstraction from reality, and therefore some of the complexity of the real situation has had to be stripped away in order to concentrate on the essential aspects. The most important property of the model, and at the same time the measure of its practical applicability, is the fact that it is capable of analysing both existing and hypothetical phenomena. It is also capable of providing information which could not other- 
wise be achieved, and thus of enabling the phenomena to be analysed in a more appropriate manner, and allowing better conclusions to be reached.

One advantage of the methods used here is that in their basic form they enable analyses to be made which are independent of the present structure of spheres of influence, and it is also possible to incorporate complementary information on the spatial structure, regional divisions and constraints on optimal solutions, as is done here to some extent. The assumption of a discrete distribution of spatial data limits the exactness of the present optimal solutions, but this problem can be reduced by increasing the number of nodes employed. In cases where the initial data cannot be represented sufficiently reliably in graph form, there is no alternative but to abandon the use of such methods. This property of discreteness can frequently be an advantage, however. Spatial interactions tend to form a network of channels of interaction in the manner of the edges on a graph, in which case graph theory provides a more suitable point of departure for the optimization process than does a euclidean space. Similarly it is sufficient in most cases to calculate indices or optimal locations for individual nodes.

\section{REFERENCES}

Aira, M., A. Kamppinen, N. Melolinna \& S. Siirilä (1972). Pirkanmaan "terveyskeskusten" optimaalinen sijoittaminen. University of Tampere, Institute of Social and Economic Ecology, Research Reports 13. 14 pp. Tampere.

Ajo, Reino (1946). Liikennealueiden kehittyminen Suomessa, Fennia 69:3. 123 pp.

Appel, K. \& W. Haken (1977). Every planar map is four colourable. Part I: Discharging. With J. Koch Part II: Reducibility. Illinois Journal of Mathematics 21, 429-567.

Breheny, Michael J. (1978). The measurement of spatial opportunity in strategic planning. Regional Studies 12, 463-479.

Bunge, William (1966). Theoretical Geography. 2nd ed. Lund Studies in Geography C 1. 289 pp. Lund.

Christaller, Walter (1933/1966). Central Places in Southern Germany (transl. 1966 Carlisle W. Baskin). 230 pp. Prentice-Hall, Englewood Cliffs.
The methods used succeeded in distinguishing well between areas of differing accessibility, and the results obtained here using different methods and assumptions are fairly consistent, enabling a reasonably unambiguous interpretation to be put forward. The results also conform well with those of previous studies in spite of differences in approach and methods.

Graph theory thus offers a methodological and theoretical framework for the further development of the technique of spatial optimization. Dynamic and stochastic graphs are applicable to optimization studies using variable time dimensions, and also to the evaluation of historical development, and differentiation and the use of constraints facilitate the solution of more complex problems and enable us to operate at levels closer to reality.

\section{ACKNOWLEDGEMENTS}

The author is indebted to Professors Juhani Hult, John Holmes and Arvo Naukkarinen for kindly reading the manuscript, and to $\mathrm{Mr}$. Malcolm Hicks, M.A., for preparing the English version of the text.

Christofides, Nicos (1975). Graph theory. An Algorithmic Approach. 400 pp. Academic Press, London.

Committee Report (1953). Aluejakokomitean mietintö. Komiteanmietintö 4. Helsinki.

Committee Report (1960). Tampereen läänikomitean mietintö. Komiteanmietintö B 38. Helsinki.

Committee Report (1962). Satakunnan läänikomitean mietintö. Komiteanmietintö B 6 . Helsinki.

Committee Report (1965). Turun lääninkomitean osamietintö I. Komiteanmietintö B 57. Helsinki.

Committee Report (1967). Keski-Pohjanmaan lääninkomitean mietintö. Komiteanmietintö B 13 . Helsinki.

Committee Report (1970). Maakuntaitsehallinnon voimaan saattaminen. Kunnallisen yhteistoiminnan järjestysmuotokomitean IV mietintö. Komiteanmietintö A 7. Helsinki.

Committee Report (1974). Väliportaanhallintokomitean mietintö. Komiteanmietintö 98. Helsinki. 
Committee Report (1977). Suunnittelu ja seuranta osana lääninhallitusten johtamista. Lääninhallitustoimikunnan mietintö. Komiteanmietintö 51. Helsinki.

Committee for Revision of the Provincial Boundaries (1978). Lääninrajojen tarkistustoimikunnan mietintö. The Ministry of Internal Affairs. Helsinki. Mimeo.

Consultative Board on Commune Boundary Revisions (1970). Kuntauudistuksen neuvottelukunnan ehdotus tarkistuksiksi lääninhallitusten kuntauudistusta koskeviin suunnitelmiin. Kuntauudistuksen neuvottelukunta. Helsinki.

Dacey, Michael F. (1965). The geometry of central place theory. Geografiska Annaler 47 B, 111 -124 .

Deo, Narsingh (1974). Graph Theory with Applications to Engineering and Computer Science. 478 pp. Prentice-Hall, Englewood Cliffs.

Eliot-Hurst, Michael E. (1972). A Geography of Economic Behaviour. An Introduction. 427 pp. Wadsworth, Belmont.

Garrison, William L. (1960). Connectivity of the interstate highway system. Papers and Proceedings of the Regional Science Association 6, $121-137$.

Gould, Peter (1969). Spatial diffusion. Commission on College Geography. Resource Paper 4. Washington.

Haggett, Peter \& Richard J. Chorley (1974). Network Analysis in Geography. 348 pp. Edward Arnold, London.

Hakala, Juhani (1973). The availability of centralplace services and the network of central places in Finland. Publicationes Instituti Geographici Universitatis Ouluensis 45. 28 pp. Oulu.

Hakimi, S. L. (1965). Optimum distribution of switching centers in a communication network and some related graph theoretic problems. Operations Research 13, 462-475.

Hautamäki, Lauri (1972). Preliminary methods in seeking optimal system of centres applied to supraprovincial level. Fennia $112.25 \mathrm{pp}$.

Ingram, D. R. (1971). The concept of accessibility: a search for operational form. Regional Studies $5,101-107$.

Isard, Walter (1956). Location and Space-Economy. 350 pp. Cambridge, Mass., and London: The M.I.T. Press.

Jarkko, Martti (1978). Telephone interview. The Ministry of Internal Affairs.

Jutikkala, E. (ed.) (1959). Suomen Historian Kartasto. WSOY, Helsinki.

Kangas, K. (1974). Optimointimenetelmien käytöstä alue- ja yhdyskuntasuunnittelussa. University of Tampere, Institute of Regional Science B 22.24 pp. Tampere.

Kansky, K. J. (1963). Structure of transportation networks. The University of Chicago, Department of Geography, Research Paper 84. 155 pp. Chicago.

Korpelainen, Eero \& Markku Tykkyläinen (1978). Verkkoteorian ohjelmia. University of Joensuu, Publications of Social and Regional Sciences 6. 60 pp. Joensuu.

Lee, Douglas B., Jr. (1973). Requiem for largescale models. Journal of American Institute of Planners 39, 163-178.
LTT (1967). Liiketaloustieteellinen tutkimuslaitos. Suomen keskus- ja vaikutusaluejärjestelmä. Publications of the National Planning Office A 19.134 pp. Helsinki.

Lösch, August (1940/1954). The Economics of Location. (transl. 1954). 520 pp. Yale University Press, Forge Village.

Map of Finland (1923). Suomen Kartta. Maanmittaushallitus. Helsinki.

Marchand, Bernard (1973). An introduction to the topological analysis of geographical spaces: the topology of central place theory. Geographical Analysis 5: 3, 205-213.

Medvedkov, Yu. V. (1967). An application of topology in central place analysis. Regional Science Association: Papers, XX, Hague Congress, $77-84$.

Mikkonen, Kauko (1975). Causal analysis of the system of the central places and prediction of functional regional structure in the administrative province of Vaasa, Finland. Fennia 138. $162 \mathrm{pp}$

Motorist's Road Map (1978). Autoilijan tiekartta. Maanmittaushallitus. Helsinki.

Nurminen, Eero (1976). Kunnan ala-asteen kouluverkon spatiaalinen rakenne ja sen optimoiminen. Licentiate's thesis. Department of Regional Science, University of Tampere.

Nystuen, John \& Michael F. Dacey (1961). A graph theory interpretation of nodal regions. Papers and Proceedings of the Regional Science Association $7,29-42$.

Optimization of School Places (1973). Koulupaikkojen optimointitutkimus. Koulusuunnittelutoimikunta. Lahti.

Ore, Oystein (1963). Graphs and their Uses. Random House and The L. W. Singer Company.

Paelinck, Jean \& Peter Nijkamp (1975). Operational Theory and Method in Regional Economics. 473 pp. Saxon House, Frome and London.

Palomäki, Mauri (1968). On the concept and delimitation of the present-day provinces of Finland. Acta Geographica 20: 20, 279-295.

Palomäki, Mauri (1972). Suomen hallinnollisen aluejaotuksen uudistussuunnitelmat ja toiminnallinen aluerakenne. Proceedings of the Vaasa School of Economics, Research Papers 8. 35 pp. Vaasa.

Palomäki, Mauri \& Kauko Mikkonen (1972). An attempt to simulate an optimal network of central places in Finland. Acta Wasaensia 2. $50 \mathrm{pp}$. Vaasa.

Report of the Working Group on Regional Government Boundaries (1976). Väliportaan hallinnon aluejakotyöryhmän mietintö. The Ministry of Internal Affairs. Helsinki. Mimeo.

Road Map of Finland. Suomen tiekartta 1 : 200000 , sheets 1-19. Maanmittaushallitus. Helsinki.

Robertson, Isobel M. L. (1976). Accessibility to services in the Argyll district of Strathclyde: a locational model. Regional Studies 10, 89-95.

Robertson, Isobel M. L. (1978). Planning the location of recreation centres in an urban area: a case study of Glasgow. Regional Studies 12, 419-427.

Rushton, Gerard (1972). Map transformations of point patterns: central place patterns in areas 
of variable population density. Papers of the Regional Science Association 28, 111-129.

Seppälä, Yrjö (1973). Matemaattinen yhdyskuntasurnnittelu. 150 pp. Tammi, Helsinki.

STV = Suomen tilastollinen vuosikirja (Statistical Yearbook of Finland) 1977. Central Statistical Office of Finland, Helsinki 1978.

Takanen, Ilpo (1972). Väliasteen aluejako ja toiminnot. Helsinki.

Törnquist, Gunnar, Stig Nordbeck, Bengt Rysted
\& Peter Gould (1971). Multiple location analysis. Lund Studies in Geography C 12.86 pp. Lund. Wachs, Martin \& T. Gordon Kumagi (1973). Physical accessibility as a social indicator. SocioEconomic Planning Sciences 7, 437-456.

Vuoristo, Kai-Veikko (1967). Suomen maaliikenneverkkojen analysointia. Terra 79, 87-94.

Vuoristo, Kai-Veikko (1977). Tieverkko talousmaantieteellisenä elementtinä. In Suomen teiden historia II, 527-584. Helsinki. 